\title{
Antibacterial action of nanoparticles by lethal stretching of bacterial cell membranes
}

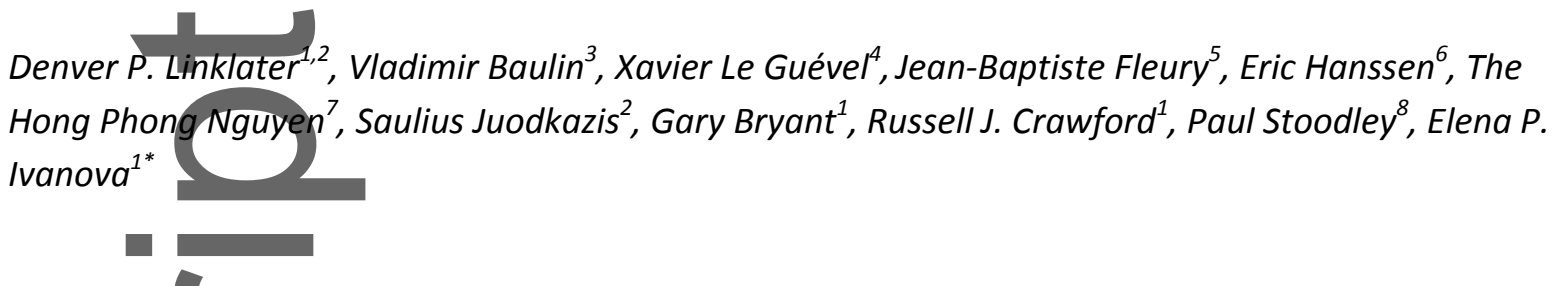

Dr. D.P. Linklater, Prof. G. Bryant, Prof. R.J Crawford, Prof. E.P Ivanova

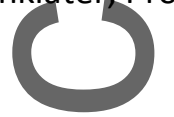

${ }^{1}$ School of Science, RMIT University, P.O. Box 2476, Melbourne, Victoria 3001, Australia.

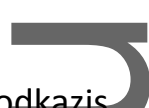

Prof. S. Juodkazis

${ }^{2}$ Opical Sciences Centre, Swinburne University of Technology, Hawthorn, Victoria 3122, Australia

Dr. V. Baulin

${ }^{3}$ Department d’Enginyeria Quimica, Universitat Rovira i Virgili, 26 Av. dels Paisos Catalans, 43007 Tarragona, Spain

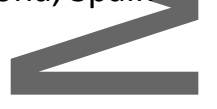

Dr. X. Le Guevel

${ }^{4}$ Insitute for Advanced Biosciences, University Grenoble-Alpes, Allee des Alpes, 38700 La Tronche, France

Dr. J. Fleury

${ }^{5}$ Saarland University, Experimental Physics and Center for Biophysics, 66123 Saarbrücken, Germany

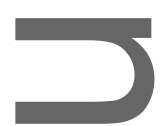

This is the ant manuscript accepted for publication and has undergone full peer review but has not been thi woh th copyediting, typesetting, pagination and proofreading process, which may lead to differences betr this version and the Version of Record. Please cite this article as doi: 10.1002/adma.202005679.

This article is protected by copyright. All rights reserved. 
A. Prof. E. Hanssen

${ }^{6}$ Advanced Microscopy Facility, Bio21 Institute, University of Melbourne, 30 Flemington Rd, Victoria 3010, Australia

Dr. T. Nguyen

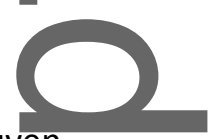

${ }^{7}$ Faculty of Applied Sciences, Ton Duc Thang University, Ho Chi Minh City, Vietnam

$(3)$

Prof. P. Stoodley

${ }^{8}$ Infectious Diseases Institute, The Ohio State University, 716 Biomedical Research Tower, 460 West 12th Avenue, Columbus $\mathrm{OH} 43210$

E-mail: elena.ivanova@rmit.edu.au
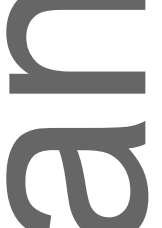

Keywords: mechano-bactericidal, nanoparticles, nanotoxicity

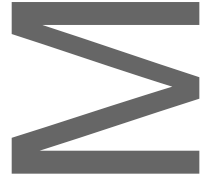

It is commonly accepted that nanoparticles can kill bacteria; however, the mechanism of<smiles>[AlH2]</smiles>

antimicrobial action remains obscure for nanoparticles that are unable to be translocated across the bacterial cell membrane by the passive or active processes that exist for mammalian cells. In this study, we demonstrate that the increase of membrane tension provoked by the adsorption of nanoparticles (NPS) is responsible for mechanical deformation of the membrane that leads to cell

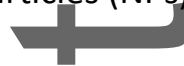

rupture and consequent bacterial cell death. We present a biophysical model of the NP-membrane interactions. The theoretical model suggests that adsorbed NPs can lead to global stretching and squeezing of the membrane. This general phenomenon was revealed experimentally using both

This article is protected by copyright. All rights reserved. 
model membranes and bacterial cells. Hydrophilic and hydrophobic quasi-spherical and star shaped gold (Au)NPs were synthesised to explore the antibacterial mechanism of non-translocating AuNPs in vitro. Direct observation of nanoparticle-induced membrane tension and squeezing was realised by a custom-designed microfluidic device that revealed the contraction of the model membrane surface area that resulted in the eventual collapse of the lipid bilayer. Quasi-spherical nanoparticles exhibited a greater bactericidal action due to a higher interactive affinity that resulted in higher degrees of membrane stretching and rupturing, as confirmed by the theoretical model. Electron microscopy techniques were used to characterise the nanoparticle-bacterial-membrane interactions. This combination of experimental and theoretical results confirmed the proposed mechanism of membrane-tension-induced (mechanical) killing of bacterial cells by non-translocating NPs.

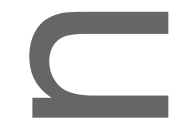

\section{Introduction}

Nanoparticles (NPs) are heavily used in biomedical, industrial, and commercial applications due to the benefits associated with the specific physical and chemical properties of both the bulk and the nanoscale material. The antimicrobial activity of NPs is widely recognised, but the mechanisms of their underlying toxicity remains unclear despite repeated attempts to establish a structure-function relationship between their physico-chemical properties and their interactions with biological systems. ${ }^{[1,2]} \mathrm{NP}$ uptake in mammalian cells is generally considered to be an active process, mediated by endocytosis. Indeed, transport across the cell membrane and intracellular accumulation dictates the nanoparticle fate and cytotoxicity. ${ }^{[3]}$ The critical size for NPs non-disruptively (passively) crossing cellular membranes is below $10 \mathrm{~nm}$, irrespective of surface functionalisation, ${ }^{[4-7]}$ Figure 1. For this reason, there is a slowly forming consensus that smaller NPs bear greater toxicity than larger ones ${ }^{[8,}$ ${ }^{9]}$. Similarly, the antibacterial properties of small NPs have been linked to the formation of large This article is protected by copyright. All rights reserved. 
irreversible pores during their translocation across the bacterial cell membrane ${ }^{[10-12]}$ At the same time, there has been an increasing number of communications that have reported the killing of bacteria with NPs in the range of $80-100 \mathrm{~nm}$ that are unable to freely translocate across the bacterial cell membrane. ${ }^{[13-17]}$ The mechanism of antibacterial activity of this size NP has yet to be clearly identified, since the variability in parameters such as concentration, dimensions, physical and chemical properties, as used in different studies, have not produced consistent results. ${ }^{[2,18]}$ The mechano-bactericidal activity of nanomaterials is a new area of research, which promises to combat bacterialadhesion, biofilm formation, and infections with comparable effectiveness to traditional antibacterial methods. ${ }^{[19-21]}$ The emergence of antibiotic resistance in pathogenic bacteria over the past few decades has posed a severe risk to public health ${ }^{[22,23]}$. Likewise, the decrease in the development of new antibiotics, for which bacteria have not yet developed a resistance, calls for the development of innovative techniques to combat multi-drug resistance. This new route of designing antibacterial nanomaterials exploits nanostructure geometry to deliver deadly mechanical forces to bacterial cells. The mechano-bactericidal antimicrobial effect was first exhibited in nature, as a topographical characteristic of insect wings ${ }^{[21,24,25]}$ The pioneering research in this area has mostly focused on the synthesis of biomimetic nanopillars and nanospikes on surfaces to create mechanobactericidal topographies. ${ }^{[26-28]}$ Nanostructures at the surfaces of bactericidal patterns can rupture bacterial cell walls by stretching the membrane that is adsorbed on the pattern ${ }^{1}$. This mechanism also works for gold-coated natural bactericidal surfaces ${ }^{2}$, showing that it is geometrical parameters of nanostructures that are key factors for this mechanism, not specific interactions or chemical components that are usually attributed to be responsible for the nanotoxicity of nanomaterials. The rupture of cell membranes under mechanical stress is an integral component of the toxicity of

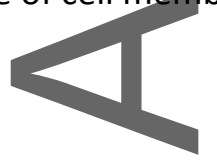

This article is protected by copyright. All rights reserved. 
nanomaterials; however, the fundamental mechanisms by which NPs might induce mechanical rupture of biological membranes has not yet been determined.

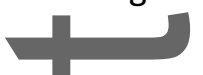

In this study, we provide evidence of the (mechano-)bactericidal mechanism of non-translocating NPs. The development of a biophysical model shows that the adhesion of large, chemically inert NPs leads to increased tension and consequent rupture of the bacterial cell membrane, Figure 1B. This proposed mechanism was studied in two independent systems: a model membrane in a customdesigned microfluidic platform, and in vitro bacterial cell experiments. (Cryo)-transmission and scanning electron microscopy were employed to visualise the impact of spherical and star-shaped NPs of approximately $100 \mathrm{~nm}$ in diameter on the viability of Pseudomonas aeruginosa ATCC 9721 and Staphylococcus aureus CIP $65.8^{\top}$ bacterial cells. The contraction (squeezing) of the lipid bilayer by adsorbed AuNPs of varying surface hydrophobicity and shape and eventual rupture was demonstrated in both systems.

\section{Results}

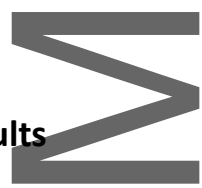

\subsection{Stretching of elastic membranes by adhering NPs}

We present a biophysical model of the adhesion of large nanoparticles to a lipid bilayer to evaluate the effects of the clusters of different size vs. individual NPs on the stretching of the elastic layer and determine the effects of NP aggregation (clustering) on global membrane stretching. Within this model, the membrane is described as an infinite elastic layer characterized by elastic modulus $\boldsymbol{k}$. The

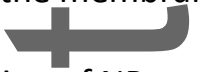
adsorption of NPs to the elastic layer is described by the interaction parameter, $\boldsymbol{\varepsilon}$ per adsorption site, while the density of adsorption sites $\boldsymbol{n}_{\mathbf{0}}$ is assumed to be constant on the surface of NPs. It turns out that these parameters can be absorbed in one dimensionless control parameter $\zeta=-\frac{\varepsilon_{0} n_{0}}{k}$ This article is protected by copyright. All rights reserved. 
that describes the interaction with a surface of a NP. Within this model $\zeta$ describes the interplay between attractive forces and elastic deformation of the membrane bilayer that leads to an equilibrium stretching of the elastic layer and partial wrapping of the spherical NPs by the elastic layer i.e. membrane stretching-compression.

\subsubsection{Individual NPs}

The interaction of non-interacting individual NPs with an elastic layer is considered in the approach similar to the construction of Wigner-Seitz cells as a result of Voronoi decomposition of the surface with individual NPs in the center of the cell. In average, an area that corresponds to an adsorbed NP is determined by the average density of adsorbed NPs at the membrane (Figure 2). Then the area that corresponds to each NP is divided in two regions for the sake of simplicity: A is the region of cell wall interacting with the surface of the NP and B is the region of the cell wall between each adsorbed NP (Figure 2A). Local stretching-compression of the elastic layer is determined by the balance between two energies: the attraction energy to the surface of the NPs, characterized by the energy gain

$$
F^{\text {gain }}=\int_{A} \varepsilon n(r) d \sigma
$$

and energy loss due to stretching of the area between NPs and compression on the surface of the $N P$,

$$
F^{\text {loss }}=\int_{A+B} \frac{k}{2} \alpha^{2}(r) \frac{n(r)}{n_{0}} d \sigma
$$

Here $n(r)$ is the density of attraction points at the surface in the position $r$ and $d \sigma$ is the element of the surface of the NP, $\alpha(r)$ is the local stretching at the point $r$. The resulting free energy after

This article is protected by copyright. All rights reserved. 
minimization with the constraint that the projection of unperturbed and stretched areas on the surface plane remains constant, yields

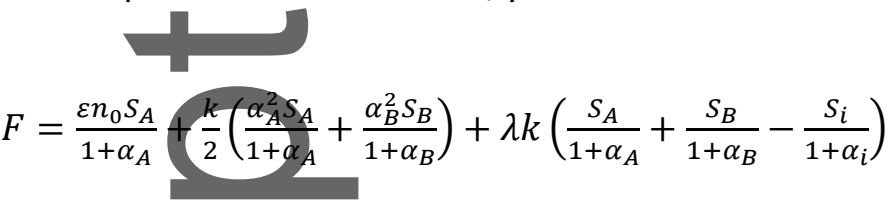

where index $i$ indicates the initial values of area $S$ and stretching $\alpha$. Here $\lambda$ is the Lagrange multiplier, which ensures the conservation of the area to the initial area $S_{0}$

$\int_{\mathrm{A}+\mathrm{B}} \frac{\mathrm{d} \sigma}{1+\alpha(\mathrm{r})}=\mathrm{S}$

The above equations allow for calculation of the stretching and compressions of two regions, $A$ and $\mathrm{B}$, considering that the stretching is uniform throughout the whole region, which is a reasonable approximation for an elastic layer.

The tension of the membrane $\Sigma$ is related to relative stretching of non-adsorbed part of the

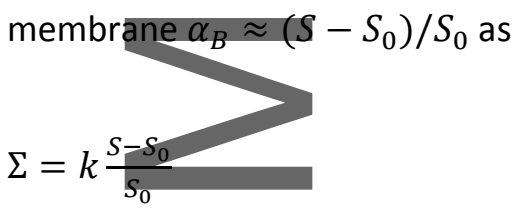

where $S$ is the actual area of the membrane under tension and $S_{0}$ is the area of a unstressed membrane. Since the lipid bilayer stretching constant is known, $k=100 \mathrm{mN} \mathrm{m}^{-1}$, the tension of the membrane and the relative area change are directly related.

Non-aggregating individual NPs interact with the bilayer independently, thus providing an additive effect on stretching and scaling linearly with the number of adsorbed nanoparticles. Therefore, to compare the stretching of NPs of different sizes it is practical to fix the surface fraction of NPs at the membrane, thus comparing equal numbers of NPs at the surface. As a reference, we choose the This article is protected by copyright. All rights reserved. 
density close to saturation of $100 \mathrm{~nm}$ NPs, when the distance between each NP is equal to the NP diameters and use this corresponding fraction for NPs of other diameters. Stretching of the membrane as a function of NPs diameters are shown in Figure 2 for different dimensionless parameters $\zeta$ describing the attraction to the bilayer and initial stretching $\alpha_{i}$.

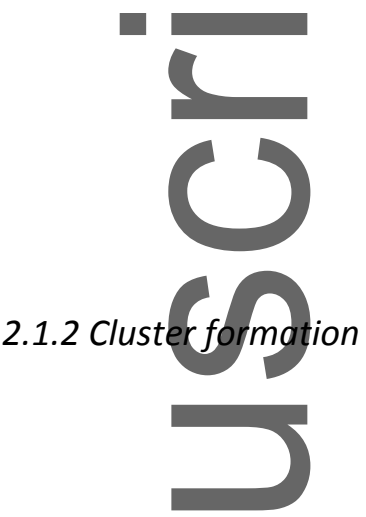

To evaluate the effect of clustering on the application of forces to the membrane, we assume that the AuNPs are grouped in clusters of spherical shape and $C(N)$ is the distribution function of clusters containing N N S.

For equilibrium distribution of clusters, the free energy of clusters is given by the mean field expression $F=k T \sum_{N=1}^{\infty} C(N)\left[\ln C(N)-1+N \epsilon_{N}\right]$ where $\epsilon_{N}$ is the energy in terms of $k_{B} T$ of the cluster containing N NPs, $k_{B}$ is Boltzmann constant and $T$ is the temperature. For spherical clusters it is given by: $\epsilon_{N}=\epsilon_{\infty}^{0}+\frac{\delta}{N^{\frac{1}{3}}} \cdot{ }^{5}$ Here $\epsilon_{\infty}^{0}$ is the bulk energy and $\delta$ is the cohesive energy per NP. Minimization of the free energy with respect to $C(N)$ leads to the equilibrium cluster distribution $C(N) \sim\left[C(1) e^{\delta}\right]^{N}$

This article is protected by copyright. All rights reserved. 
with the average size of the cluster $\bar{N} \sim \sqrt{\sigma e^{\delta}}$, which depends on the surface density of NPs at the membrane $\sigma$. For spherical aggregates, the distribution $C(N)$ is sharply peaked around the average ing

size. Thus, in the following, we will consider a monodisperse distribution of clusters around the average size where, $N$ is the average size of the cluster. Thus, assuming dense packing of NPs in the clusters, the radius of a spherical cluster is given by $R=r N^{\frac{1}{3}}$, where $r$ is the radius of an individual nanoparticle. With this, the surface density of the clusters $\phi$ of equal size is related to the surface density of the nanoparticles $\sigma$, adsorbed at the surface as

$\phi=\sigma\left(\frac{R}{r}\right)^{-3}$

In the case of individual NPs, $\phi=\sigma$, but if the NPs are aggregated in large clusters, the surface density of clusters is significantly lower than surface density of individual NPs. However, the stretching of the membrane by large clusters is larger than that imposed by the individual NPs. The modelof interaction of clusters with the elastic layer has the following parameters: the elastic layer is described by the elastic modulus $k$, and the clusters are described by the diameter, $D=2 R$, the attractive interaction to the surface, $\varepsilon$, and the surface density of clusters, $\phi$. For a fixed interaction parameter $\varepsilon$, layer stretching as a function of the surface density of clusters and cluster diameter is shown in Figure 2D.

We assume that individual NPs and clusters do not interact at the surface and are distributed equally in repetitive arrangement (pure translation) in unit cells. This approximation allows us to study a single cluster of variable size in a square box with periodic boundary conditions (Figure 2). The area of the box $L^{2}$ is then translated in the density of clusters, $\phi \sim \frac{1}{L^{2}}$. Although this approximation neglects cooperative effects and interactions between nanoparticles and clusters, this is a good first

This article is protected by copyright. All rights reserved. 
approximation for comparison of effects of clustering on the local and global stretching of the lipid bilayer.

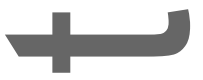

As expected, membrane stretching is increased with increased cluster diameter and the density of clusters, which corresponds to a higher concentration of NP. In turn, higher interaction parameters<smiles>[CH]1CC1</smiles>
lead to greater membrane stretching. However, it is more interesting to represent these results as a function of a surface density of the nanoparticles composing the cluster, $\sigma$, as seen in Figure 2C. These plots indicate that if the number of NPs attached to the surface is fixed, the cumulative stretching is higher for dispersed individual NPs (maximum at smaller cluster diameters) than for NPs aggregated in clusters (Figure S2). Nevertheless, the stretching exerted by one large cluster increases with the size of the cluster (Figure 2D, $\phi=0$ ) and one large cluster alone can rupture the membrane

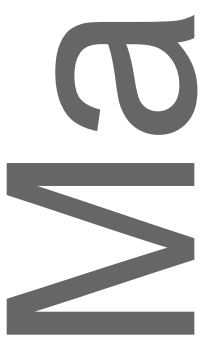

\subsection{Large NPs clusters induced membrane stretching in model lipid bilayer}

Nonspecific attractive forces that promote nanomaterial-membrane interactions are mediated by inherent nanomaterial characteristics such as surface charge, hydrophobicity, and roughness.

Hydrophobic NPs tend to agglomerate and are therefore less likely to undergo membrane interactions. However, for more hydrophilic nanomaterials, surface membrane interactions may be determined by their relative hydrophilicities. Membrane interactions can also be affected by nanoscale surface roughness. NP surface protrusions or depressions have been shown to NP affinity

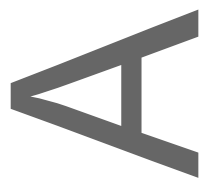

This article is protected by copyright. All rights reserved. 
for the cell membrane. Simulations of NP-membrane interactions show that NP surface roughness greatly minimizes repulsive interactions, thereby promoting adhesion. ${ }^{[30,31]}$

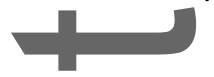

In the present work, hydrophilic and hydrophobic $100 \mathrm{~nm}$ quasi-spherical (AuNSPs) and star (AuNSTs) shape AuNPs were synthesised to explore the antibacterial mechanism of non-

-

translocating AuNPs as a function of size, shape, and surface charge. ${ }^{[5,32]}$ The surface charge and chemical properties of the NPs were determined by capping agents which play a crucial role in controlling the interactions between bacteria and the NPs (Figure 3). Hydrophilic AuNPs were coated with mercaptohexanoic acid (MHA) while hydrophobic AuNPs were stabilized with a modified sulfobetaine ligand (ZwBuEt). ${ }^{[33]}$

To visualise the adsorption of quasi-spherical and nanostar AuNPs onto a model lipid membrane, a novel 3D $\mu$ chip was developed (Figure S3), in which a lipid bilayer was formed through the sandwiching of lipid in oil phase (DOPC:DOPS+squalene) between two water phases. The bilayer is stable at least for $2 \mathrm{~h}$. The lipid bilayer formed (final diameter $200 \pm 10 \mu \mathrm{m}$ ) upon drainage of the oil phase at the intersection of the upper well and the bottom channel and can be viewed optically.

AuNPs were introduced into the $\mu$ chip upper well and attachment to the bilayer was visually recorded over a period of 30 min by dark field microscopy.

The AuNSP and AuNST functionalized with MHA or ZwBuET were studied independently. In Figure 4, the lipid bilayer annulus is clearly visible, and its shape could be approximated to a free-standing quasi-2D circle with radius, $r$, and area $A=\pi r^{2}$. As seen in Figure $4 A$ and $B$, the bilayer area diminished with time due to the presence of the AuNSP that were adhering permanently to the entire surface of the lipid bilayer (for MHA and ZwBuET ligand). By contrast, AuNST were found to adhere permanently only at the lipid bilayer annulus (just at the lipid-oil/water interface), and they

This article is protected by copyright. All rights reserved. 
did not strongly adhere to the lipid membrane (see Figure S4). AuNST were unable to place the same amount of tension on the lipid membrane with time (for AuNST with either MHA or ZwBuET ligands) to cause a contraction of the bilayer area. The spontaneous bilayer contraction by AuNSP adsorption was also investigated for smaller AuNSPs with effective diameters of 20 and $50 \mathrm{~nm}$ (Figures S5). Thus, the phenomena of the NP-induced contraction of the free-standing lipid bilayer exists for a large of NP size range.

As seen in Figure $4 C$ and $D$, by plotting the bilayer radius as function of time, we calculated that the bilayer radius diminished at a rate of $1.4 \mu \mathrm{m} \mathrm{s}^{-1}$ for both AuNSP-ZwBuEt and AuNSP-MHA (at the concentration of $100 \mathrm{\mu g} \mathrm{Au} \mathrm{mL}{ }^{-1}$ ); which corresponded to a reduction of approximately $0.7 \%$ (of the bilayer total radius) per second. Under our experimental setup, on average, both NPs appeared to consistently shrink the bilayer at a similar rate with the bursting time between 100 and 200 s when the bilayer radius reached $\sim 75 \mu \mathrm{m}$. The estimated tension $(\Delta T)$ force was in the order of approximately 0.1-1 $\mathrm{mN} \mathrm{m}^{-1}$ (See Supplementary Results).

To quantify the stretching and disruption of the membrane because of quasi-spherical NP attachment, the model membrane was supported in a custom-designed microfluidic set-up (Figure 4A); the formation of the DOPC: DOPS lipid bilayer was confirmed by electrophysiological measurements, which give the capacitance of the bilayer. Capacitance values could be normalised according to the bilayer area. To express the results in specific capacitance $C_{s}$ values, with $C_{s}=5.9$ $\mathrm{mF} \mathrm{m}{ }^{-2}$ for the DOPC: DOPS (9:1) bilayer. Using the electrical replacement circuit of a plate capacitor, the DOPC layer thickness could be calculated as $d \approx \varepsilon_{0} \varepsilon_{L} / C_{S} \approx 3.3 \mathrm{~nm}$, with vacuum permittivity $\varepsilon_{0} \approx 8.85 \times 10^{-12} \mathrm{~F} \mathrm{~m}^{-1}$ and $\varepsilon_{L} \sim \varepsilon_{o i l} \sim 2.2 .{ }^{[33,34]}$ Thus, the specific capacitance of the pure bilayer should decrease if AuNPs were either fully or partially inserted into the membrane. ${ }^{[33]}$ From

This article is protected by copyright. All rights reserved. 
the values of the surface tension and the bilayer contact angle $\theta$, which were obtained from pendant drop measurements or optical micrographs (Figure 5), respectively, the bilayer tension could be - 1

calculated using Young's equation (see Materials and Methods).

As can be seen in Figure 4B, there is a significant increase in the as-measured bilayer tension

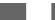

between experiments with no NPs and with AuNSPs. AuNSP-MHA achieved the largest increase in membrane tension. When the experiment was conducted over a range of concentrations $(50-200$ $\mu \mathrm{g} \mathrm{Au} \mathrm{mL}{ }^{-1}$ ) there was a linear increase in the measured bilayer tension (Figure S6). Similarly, when analysing the capacitance measurements, there is a general decline in membrane bilayer capacitance when AuNSP functionalised with ZwBuEt and then MHA is introduced to the system. This corresponds to attachment, or partial or full insertion of the NP into the model bilayer ${ }^{[35]}$. Furthermore, to confirm physical contact with the membrane by AuNSP-MHA/ZwBuEt, a fluorescent lipid bilayer composed of $3 \%$ DOPC-Rho and $5 \mathrm{mg} \mathrm{mL}^{-1}$ DOPS extract, was monitored using a fluorescence microscope. The bilayer appeared bent for mechanical stability (Figure 4A). The AuNSP functionalised with MHA appeared to be fluorescent for $30 \mathrm{~min}$ following interaction with the lipid bilayer (these interactions were recorded, Supp. Movie File 1), thus indicating that the AuNSPs were adsorbed to the cell membrane.

\subsection{NPs induced membrane stretching and antimicrobial activity in vitro}

Synthetic lipid bilayers are a convenient model system for NP-membrane interactions that enable detailed physical insight to be obtained thanks to their relative structural simplicity and wellcharacterized properties; however, real biological membranes are far more complex in structure. In this section we describe the interaction of large NPs with bacterial cells and demonstrate the stretching effect on bacterial cell membranes.

This article is protected by copyright. All rights reserved. 
To assess the antimicrobial activity of the two types of AuNPs studied in the model system, the following parameters/factors were considered and investigated: (i) the influence of surface hydrophobicity, (ii) the impact of the concentration of the NPs $\left(25,50,100\right.$ and $200 \mu \mathrm{g} \mathrm{Au} \mathrm{mL}{ }^{-1}$ ), (iii) kinetics of bactericidal activity over time, and (iv) the effect of shape (quasi-spherical or star).

Analysis of the bactericidal activity (Figure 6) indicated that quasi-spherical AuNPs with increased hydrophobicity showed less antimicrobial efficiency towards both gram-negative $P$. aeruginosa and gram-positive S. aureus. Indeed, no significant reductions in viable bacteria were noted for $P$. aeruginosd when (Figure 6A). By contrast, hydrophilic AuNSP-MHA achieved complete inactivation of both bacterial species after a $30 \mathrm{~min}$ incubation period at concentrations $\geq 100 \mu \mathrm{g} \mathrm{Au} \mathrm{mL}{ }^{-1}$ (Figure $6 \mathrm{~A}, \mathrm{~B})$; significant reductions $\left(p<0.02\right.$ ) in CFU mL ${ }^{-1}$ were observed at concentrations $\geq 10 \mu \mathrm{g} \mathrm{Au} \mathrm{mL} \mathrm{L}^{-1}$ (Figure S7). The differences in antibacterial activity may be attributed to the variable affinities (due to altered hydrophobicity) of the AuNPs towards bacterial cells. Bidentate zwitterionic (hydrophobic) ligands exhibit excellent colloidal stability under conditions of high concentration, however, when the functionalized NPs are serially diluted, an increase in non-specific adsorption and aggregation has previously been noted. ${ }^{[36]}$ The zwitterionic coating may also impart novel antibiofouling properties to the nanomaterials and functionalised NPs would not exhibit non-specific adhesion to living cells ${ }^{[37]}$. In this work, under physiological conditions, MHA-NPs (hydrophilic) showed higher stability and less aggregation than ZwBuEt-NPs (hydrophobic) (Figure S1). The antibacterial efficacy of the AuNPs used in this study was also confirmed via fluorescence microscopy (Figure 6E).

In accordance with the model membrane experiments above, Au nanostars exhibited considerably less antibacterial efficacy towards both $P$. aeruginosa and S.aureus compared to that of the quasi-

This article is protected by copyright. All rights reserved. 
spherical NPs and the antimicrobial activity was not greatly affected by surface chemical functionalisation. Matching data for the antibacterial effects of AuNSTs are shown in Figure S8.

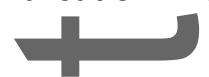

To visualise the AuNP-induced disruption of bacterial cells by AuNSPs and AuNSTs on both $P$. aeruginosd and S. aureus, electron microscopy was used to examine the morphology of the bacterial (1)

cells (Figure 7). Bacterial cells that were treated for $2 \mathrm{~h}$ with AuNPs showed severe morphological changes. Analysis of the SEM and TEM images revealed the attachment of NPs onto $P$. aeruginosa and S. aureus cell membranes, and in some cases, complete encapsulation of bacterial cells leading to the destruction of the original cell morphology (Figure 7B, C, D). NPs were observed to attach directly onto the membrane causing stretching (Figure 7A) or indentations (Figure 7B) in the membrane or complete cell lysis (Figure $7 C^{\prime}$ ).

AuNSPs (and to a lesser extent AuNSTs) adversely affect bacterial cells by inducing high local stress on the bacterial cell membrane at the time of the interactions, eventually causing lysis of the cell (as seen in Figure $\left.7 C^{\prime}\right)$. It was presumed that the cell damage was not incurred through 'internalisation' of the nanoparticles due to their large size (approximately $100 \mathrm{~nm}$ ) and no evidence of internalisation was observed, in agreement with previous studies of AuNP anchorage onto grampositive and gram-negative bacterial membranes. ${ }^{[38]}$ TEM experiments (Figure S8) show that the AuNST nanospikes are embedded in the bacterial capsule but do not have sufficient length to interact with the bacterial membrane.

Nanoparticle affinity for the bacterial membrane was determined using Cryo-TEM. The brief incubation period allowed for the initial interactions between NPs and bacteria to be visualised, as they would appear in liquid/native conditions (Figure 7G, Figure S9). The functionalisation of the NPs greatly affected the behaviour of the NPs toward bacteria and toward each other in bacterial

This article is protected by copyright. All rights reserved. 
suspension. For quasi-spherical NPs, the hydrophobic zwitterionic ligand (ZwBuEt) did not enhance the particle affinity for bacterial membranes, indeed there seemed to be almost no interaction between bacteria and AuNSP-ZwBuEt. By contrast, AuNSP-MHA appeared greatly attracted to the bacteria in suspension and could be seen encapsulating the cell, as shown in Figure 7G. Weak interactions between the phospholipid bilayer and AuNSTs were additionally confirmed using cryoEM. This result is supported by our experimental model demonstrating that nanostars exhibit weaker antibacterial activity because of reduced contact area with the cell membrane. For AuNSTs, those capped with ZwBuEt were observed in large clusters while those capped with MHA were distributed across the grid with no interaction with bacteria. This directly corresponds to the increased rates of antibacterial efficiency observed for AuNSP-MHA over AuNSP-ZwBuEt.

\section{Discussion}

It is known that the exposure of NPs to bacterial cells can lead to membrane damage caused by NP adsorption. In the case of $\mathrm{TiO}_{2}, \mathrm{CeO}_{2}, \mathrm{MgO}$ and Au-NPs, the interaction with the cell wall is the main source of toxicity to bacteria even though no cell penetration occurs (Table S3). In such cases, the NPs electrostatically adsorb onto the bacterial cell wall and destroy the cell wall due to the NP aggregation observed only at the cell surface. ${ }^{[39-42]}$ These studies suggest that NP adsorption on the cell wall followed by its disintegration is the primary reason for toxicity, although no definitive mechanisms have been put forward.

The adsorption of large NPs (where the NP diameter is greater than the thickness of the membrane) on model lipid bilayers has been studied both theoretically and experimentally. This includes studies of wrapping of NPs by lipid membranes, ${ }^{[43-46]}$ effective interactions at the surfaces and collective behaviour of adsorbed NPs. ${ }^{[47-49]}$ Electrostatic interactions between the NPs and the membrane are This article is protected by copyright. All rights reserved. 
found to be the most important factor for inducing membrane disruption. ${ }^{[29,50-52]}$ In particular, it was shown that large NPs adsorbed on lipid bilayers will always at least partially wrap ${ }^{[6,53]}$ while membrane wrapping may in turn lead to eventual collapse of the lipid bilayer. ${ }^{[54]}$ Wrapping and membranetension in the adhesion of NPs are coupled such that low tension membranes allow for higher wrapping and vice versa. ${ }^{[55]}$ Nevertheless, most membrane wrapping studies are focused on NP uptake by mammalian cells whereby membrane wrapping is triggered by many NP-ligand-surface receptor interactions for NP engulfment. Less attention has been focused on NP-membrane interactions of bacterial cells.

We recently demonstrated a mechanism of tension induced permeation of cell membranes by the adhesion of large non-translocating apatite nanoparticles that provoked nondisruptive permeation of red blood cells (that do not undertake endocytosis). ${ }^{[56]}$ In another study the internalization of large silica nanoparticles into giant unilamellar vesicles (GUVs) was confirmed to be mediated by the spreading forces of the lipid bilayer on the silica surface. The lipid membrane was observed to strongly adhere to the NP surface and 'creep' along the silica surface, causing deformation of the liposome. ${ }^{[57]}$ Similar behavior was observed for the adherence of silica particles on red blood cells. ${ }^{[58]}$ The haemolytic activity of silica NPs has been found to increase with increasing particle size due to preferential adsorption of the NPs onto the red blood cell membrane, causing deformation until rupture. ${ }^{[58,}$

In the work presented here, the antibacterial performance of the hydrophilic quasi-spherical AuNPs appears to be mediated by NP-membrane interaction which is driven by the attractive force between the NPs and the phospholipid bilayer. As the particle size increases, the adhesion energy increases, leading to a greater area of contact and overall stretching of the membrane. Individually

This article is protected by copyright. All rights reserved. 
adhered NPs provoke an additive stretching effect where the total membrane stretching is the sum of individual NP contributions. In the case of NP clusters, the stretching effect is cumulative at the attachment points but does not exceed the tensions delivered to the membrane by single, spatially dispersed NP. This agrees with a previous model of the hemolytic potential of silica NPs. ${ }^{[60]}$ In the case of clustering between individual NPs, the elastic response of the membrane depends on the size of the clusters and their number. In addition, if the clusters are placed close to each other, the membrane acts as a medium, affecting the interactions between NPs and even inducing their clustering. ${ }^{[48]}$ The developed theoretical model provides insight to explaining the results for both experiments: NPs induced tension in the model lipid bilayer and the in-vitro bacterial cell killing mechanism showing that low dispersity of NPs achieved greater antibacterial efficiency. Encapsulation of entire bacterial cells by individual NPs was visualised attached to the exterior of the cell and deforming the shape by independent experimental techniques, and in some cases, complete cell lysis was observed.

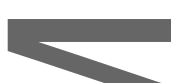

The in vitro model used to mimic the interactions of a phospholipid membrane and NPs demonstrated the delivery of tension forces that resulted in cell perturbation by the attachment of NPs onto the membrane. Previous theoretical models have predicted that NPs can translocate a tethered DOPC lipid bilayer membrane and/or become wrapped in by the membrane, depending on the balance of contact-adhesion energy and curvature energies. ${ }^{[61]}$ The minimum nanoparticle size for such wrapping effects is estimated to be $30 \mathrm{~nm}$, which represents a state of transition between free NP and partially lipid coated NP. ${ }^{[62]}$ In the work presented here, direct physical interactions between the quasi-spherical NPs (both hydrophilic and hydrophobic) and the phospholipid membrane resulted in an increase in membrane tension and decrease in capacitance of the synthetic tipid bilayer that correlated to either full or partial insertion of the NPs into the lipid This article is protected by copyright. All rights reserved. 
bilayer. Using fluorescently tagged DOPC, AuNPs were confirmed to contact the lipid bilayer (verified by consequent fluorescence of the NPs through removal of phospholipids from the bilayer);

however, no transport across the bilayer was observed yet the bilayer appeared 'bent' for mechanicalstability. Hydrophilic NPs delivered the greatest forces to the lipid bilayer upon membraneadsorption, achieving the greatest resultant membrane tension measurements. Hydrophilic quasi-spherical NPs also elicited the largest antibacterial response amongst both shaped particles achieving $100 \%$ bacterial cell death at a concentration of $100 \mu \mathrm{g} \mathrm{Au} \mathrm{mL} \mathrm{L}^{-1}$. Nevertheless, at

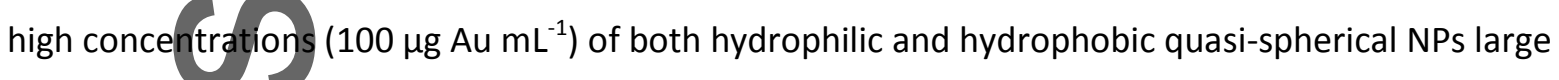
numbers of attached NPs to the lipid bilayer produced enough force to contract the membrane until it collapsed. This is analogous to the squeezing of a balloon until it bursts (see graphical abstract).

It was assumed that a greater hydrophobicity of the particle would results in greater affinity for bacterial membranes. ${ }^{[38]}$ Chemical modification by bidentate sulfobetaine zwitterionic molecules led to an increase in hydrophobicity; ${ }^{[63]}$ however, NP-membrane interactions were offset by the NP tendency to aggregate into clusters. ${ }^{[64]}$ Herein, the NPs that exhibited low dispersity, such as hydrophilic quasi-spherical NPs, also demonstrated the greatest antimicrobial effects whereas hydrophobic quasi-spherical NPs did not achieve statistically significant reductions in viable cells. Thus, the affinity of the NP towards bacterial cells played an important role in facilitating bacterial cell inactivation. It was further hypothesised that the introduction of spikes to the nanomaterial surface would result in greater cell membrane perturbation. We have demonstrated previously that nano-structuring of surfaces to exhibit an array of high aspect ratio nanoprotrusions, similar to the surface topography of insect wings, can mechanically lyse contacting bacterial cells ${ }^{[65]}$. Bacterial cell death is mediated by the membrane adsorption to the nanopillars which leads to wide-spread stretching of the adsorbed membrane ${ }^{[24]}$ (similar to the findings for global stretching of bacterial cell This article is protected by copyright. All rights reserved. 
membranes by colloidal nanomaterials presented in this study) by which the mechanism is independent of surface chemical functionality. For example, silicon nanopillar surfaces (black silicon) were the first synthetic surface demonstrated to mechanically kill attaching bacterial cells ${ }^{[19]}$. More recently, nahostructured surfaces of vertically aligned carbon nanotubes ${ }^{[20]}$, graphene nanoflakes ${ }^{[66]}$, adsorbed $\mathrm{NPS}^{[67,68]}, \mathrm{TiO}_{2}$ nanowires ${ }^{[28]}$ and more have been demonstrated to kill bacteria by nanomaterial-induced rupture. However, in this work the surface spikes did not enhance the killing effects of the AuNPs, in fact star-shaped AuNPs displayed only very modest antibacterial performance. It is assumed that the introduction of surface spikes actually led to a reduction in the available contact area of the NP surface, as confirmed by model membrane experiments where AuNSTs exhibited a reduced ability to adsorb to the lipid bilayer and were not observed to exert the same forces delivered by quasi-spherical NPs.

\section{Conclusion}

The mechanism of mechanical killing of bacterial cells by non-translocated NPs was elucidated using a combination of complementary experimental and theoretical studies. A biophysical model was developed to explain the NPs induced stretching of a membrane by large NPs with diameters much larger than the thickness of the membrane. Interactions between individual NPs and the elastic bacterial membrane induces an increase in membrane tension due to adsorption of the NPs to the membrane. ${ }^{[44,45,69]}$ The importance of membrane tension for biological membranes is not always considered for fluid membranes, while tension can be even more important for elastic membranes such as bacterial cell walls due to their lack of cytoskeleton to compensate for external mechanical forces. Attractive forces acting between each NP and the membrane tend to increase the area of contact $^{[55]}$, thus provoking the overall stretching of the membrane. Spatially distributed individual

This article is protected by copyright. All rights reserved. 
NPs provoke an additive effect, when the overall stretching is the sum of individual NP contributions, while clustered NPs created cumulative stretching at the attachment points. The cumulative effect of clustered particles may be locally stronger than the tensions delivered by a single NP; however, the combined forces administered by separated individual NPs encapsulating a cell would still be greater. Although the nature of the membranes used in both experiments are very different: the DOPC:DOPS lipid bilayer is a fluid membrane, whereas the bacterial cell wall is an elastic layer, both experiments confirmed that chemically inert AuNPs can rupture model lipid bilayer and kill bacteria via adsorption onto the cell membrane and increase of membrane tension. Such an elastic model is not limited by the type of NPs and the origin of the elastic layer. The universality of the model suggests that the described phenomenon of the stretching of the membranes by adsorbing NPs can go beyond the studied NPs and bacteria and it can be applied as a universal mechanism of mechanical stretching and rupture of cells, vesicles, droplets and other soft objects with NPs. The demonstration of this stretching mechanism in both model and real bacterial system suggests its and applic generality andapplicability to a wide range of biological membranes. The results of this work may provide new guidelines for the synthesis of universal antibacterial colloids.

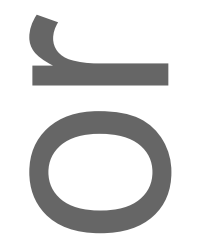

5. Experimental Section

Design and Fabrication of Microfluidic Device. Microchannels with a rectangular cross section were fabricated using typical soft lithography protocols. ${ }^{[70]}$ Channel dimensions were $300 \mu \mathrm{m}$ in width and $140 \mu \mathrm{m}$ in height. The device was moulded with a SU-8 photoresist on a silicon wafer using Sylgard 184 (Dow Corning, USA). The surface of the Sylgard 184 devices was exposed to nitrogen plasma This article is protected by copyright. All rights reserved. 
(Diener electronic $\mathrm{GmbH}$, Germany) and sealed with a plasma treated glass cover slide. The sealed device was rendered hydrophobic by heating it to $135^{\circ} \mathrm{C}$ overnight. The liquids were dispensed from syringes (Hamilton Bonaduz AG, Switzerland), which were connected to the microfluidic device by Teflon tubing. Computer controlled syringe pumps were used to control the injection of the water and oil phases, respectively (Figure S9). DOPC (1,2-dimyristoyl-sn-glycero-3-phosphocholine) and DOPS (1,2-dioleoyl-sn-glycero-3-phospho-L-serine) were purchased from Avanti Polar Lipids. Experiments were performed at room temperature to have the lipids in a fluid phase. Using a volume-controlled system with syringe pumps, two water droplets were injected face to face into microchannels to produce a free-standing lipid bilayer. After a few seconds, the water-oil interface of each finger was covered with a monolayer of lipids molecules. Once the two liquid fingers are brought into contact, the two lipid monolayers interacted to form a lipid bilayer within a short time. ${ }^{[34,71,72]}$ The system is then stable and can be analysed, simultaneously, using optical microscopy (axiovert Z1, Zeiss) and by electrophysiological inspection.

Measurement of Bilayer Tension. The surface tensions of the various lipid monolayers at oil/water interfaces were measured with the pendant drop method using a commercial measurement device (OCA 20, DataPhysics Instruments GmbH, Filderstadt, Germany). An oil solution with a concentration of $5 \mathrm{mg} \mathrm{mL}^{-1}$ lipids concentration (90\% DOPC, 10\% DOPS) was produced by introducing a droplet from a steelneedle into the surrounding oil phase. The shapes of all droplets were fitted with the Young-Laplace equation to obtain their interfacial tension $\gamma$. The experiments were then re-done in the presence of the two types of NPs (ZwBuEt and MHA). From the values of the surface tension and the bilayer contact angle $\theta$, which were obtained from pendant drop measurements or optical micrographs (see Figure 6), respectively, the bilayer tension can be calculated using Young's equation. 173$]$

This article is protected by copyright. All rights reserved. 


$$
\Gamma=2 \gamma \cos \theta
$$

Capacitance Measurements. $\mathrm{Ag} / \mathrm{AgCl}$ electrodes were prepared by inserting an electrode in a borosilicate glass pipet (outer diameter $1.5 \mathrm{~mm}$, inner diameter $0.86 \mathrm{~mm}$, Sutter) containing an electrolyte agarose solution (Sigma). The electrodes were carefully introduced into the buffer compartment of the Sylgard 184 device using a micromanipulator. The lipid membrane conductance was measured using the standard function provided by the patch clamp amplifier EPC 10 USB (HekaElectronics) A 10-mV sinusoidal wave with a frequency of $20 \mathrm{kHz}$ was used as an excitation signal.

Characterisation of AuNSP and AuNST

Spectrophotometry. UV-VIS absorption spectra of the AuNSP and AuNSTs sols were collected using a UV-1800 spectrophotometer (Shimadzu). The spectra were collected in transmission mode.

Dynamic light scattering (DLS). Hydrodynamic size measurements of the different AuNPs were performed in water using a zetasizer (Malvern Instruments).

Bacterial cell growth conditions. P. aeruginosa ATCC 9721 and S. aureus CIP $65.8^{\top}$ bacterial strains were obtained from American Type Culture Collection (Manassas, VA, U.S.A.) and Culture Institute Pasteur (Paris, France), respectively. Prior to each experiment, bacterial cultures were refreshed on nutrient agar (Oxoid) from stocks (B.D., U.S.A.) at $37^{\circ} \mathrm{C}$ for $24 \mathrm{~h}$. From the stock plate, fresh bacterial suspensions were grown overnight at $37^{\circ} \mathrm{C}$ in $5 \mathrm{~mL}$ of nutrient broth (B.D., U.S.A.). Bacterial cells were collected at the logarithmic stage of growth (data not shown). Bacterial cells were then pelleted using centrifugation at $5000 \mathrm{rpm}$ for $3 \mathrm{~min}$ and resuspended in $10 \mathrm{mM}$ phosphate buffered

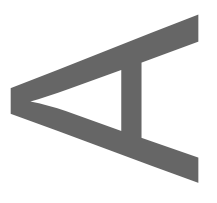

This article is protected by copyright. All rights reserved. 
saline ( $\mathrm{pH}$ 7.4). The density of bacterial suspensions was adjusted to $\mathrm{OD}_{600}=0.1$ using UV-vis spectrophotometry (Dynamica HALO RB-10) at a wavelength of $600 \mathrm{~nm}$.

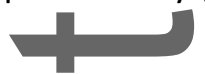

Antibacterialassay. Standard plate count methods were used to estimate the number of viable cells following treatment with AuNPs, $P$. aeruginosa and $S$. aureus stock solutions were serially diluted in phosphate buffered saline (10 mM PBS, pH 7.4) until infectious doses were achieved (1000 CFU mL ${ }^{-1}$ P. aeruginosa ${ }^{[74]}$ and $100,000 \mathrm{CFU} / \mathrm{mL}$ S. aureus $\left.{ }^{[75]}\right)$. The AuNSP and NSTs sols were sonicated for 2 min and added to suspensions of $P$. aeruginosa and S. aureus $(500 \mu \mathrm{L})$ at concentrations of $5,10,25$, 50,100 and $200 \mu \mathrm{gL}^{-1}$. Nanoparticle/bacterial suspensions were then incubated in a rotary shaker at $37 \stackrel{\circ}{ }$ for up to $2 \mathrm{~h}$ at 220 RPM. Bacterial suspensions in PBS, with no added nanoparticles, but an equal volume of MilliQ $\mathrm{H}_{2} \mathrm{O}$, were used as controls for each given concentration. The NP/bacterial suspensions and controls were then spread plated on 5 separate nutrient agar (Oxoid) plates and incubated at $37^{\circ} \mathrm{C}$ overnight to estimate the number of viable cells.

Statisticalanalysis. All plate count experiments were performed in replicates of 5 and repeated a minimum of 3 times. Data are expressed as a mean \pm standard deviation of at least 5 independent samples. Statistical comparisons were made between results using a two-tailed student's T-test where $p<0.05$ is considered significant.

Scanning Electron Microscopy. The morphology of synthesised AuNPs of various shapes and sizes were analysed using SEM (Raith, GmBH). AuNSPs and NSTs were drop-casted onto plain silicon wafers and allowed to air dry under ambient conditions overnight. SEM images were obtained using a Raith150Two direct write EBL instrument (Raith, GmBH) with SEM capabilities at $5 \mathrm{kV}$.

The morphology of bacterial cells incubated with nanoparticles was also examined using SEM (Raith, $\mathrm{GmBH}$ ). The AuNPs/bacterial suspensions were incubated for $2 \mathrm{~h}$ in a rotary shaker at $37^{\circ} \mathrm{C}$ at 220

This article is protected by copyright. All rights reserved. 
RPM and then prepared for SEM by placing a $100 \mu \mathrm{L}$ aliquot on clean silicon wafer, leaving for $1 \mathrm{~h}$ for cells to adhere to the substrate, then washing once briefly with MilliQ $\mathrm{H}_{2} \mathrm{O}$ to remove salt and other contaminants. Cells were then fixed on the substrate with $2.5 \%$ glutaraldehyde and the surfaces were then dehydrated with ethanol in $30,50,70,90$ and $100 \%$ concentrations. The substrata were kept in $100 \%$ ethanol and transferred to a critical point dryer (Polaron E3100, Quorum Technologies Ltd). The samples were immersed in liquid $\mathrm{CO}_{2}$ via a series of ethanol/liquid $\mathrm{CO}_{2}$ exchanges, and the liquid $\mathrm{CO}_{2}$ was then heated to supercritical temperature and pressure $\left(31.1^{\circ} \mathrm{C}\right.$ and $\left.1000 \mathrm{psi}\right)$. The dried samples were then sputtered with gold for 2 min using a NeoCoater MP-19020NCTR (JEOL, Frenchs Forest, Australia). SEM images were obtained using the Raith150 Two direct write EBL instrument (Raith, GmBH) with SEM capabilities at $5 \mathrm{kV}$ at magnifications of $\times 5 \mathrm{k}, \times 10 \mathrm{k}, \times 25 \mathrm{k}$ and $\times 50 \mathrm{k}$.

Transmission Electron Microscopy. Suspensions of AuNSP and AuNST sols were drop-cast onto TEM grids and viewed at an accelerating voltage of $200 \mathrm{kV}$ using a Jeol JEM-1010 machine.

TEM (JEM-1010, JEOL) was used to view cross sections of bacterial cells incubated with nanoparticles. Samples were incubated with bacteria at concentrations of $200 \mu \mathrm{g} \mathrm{mL}^{-1}$ in a rotary shaker at $37^{\circ} \mathrm{C}$ at 220 RPM for $2 \mathrm{~h}$. After incubation, cell suspensions were washed twice with PBS (10 mM, pH 7.4) using centrifugation at $1300 \mathrm{rpm}$ for $5 \mathrm{~min}$ at $25^{\circ} \mathrm{C}$. The pellets were then suspended in $2 \mathrm{~mL}$ of $1 \%$ glutaraldehyde in PBS for $1 \mathrm{~h}$, and then washed twice in PBS for $5 \mathrm{~min}$. After the final washing step, the cell suspensions were mixed thoroughly with $0.5 \mathrm{~mL}$ of molten $4 \%$ agarose gel-by stirring. The agar was then immediately cooled to $4^{\circ} \mathrm{C}$ by refrigeration for $30 \mathrm{~min}$, then cut into $1 \mathrm{~mm}^{3}$ cubes and fixed with $1 \mathrm{~mL}$ of $1 \%$ osmium tetroxide $\left(\mathrm{OsO}_{4}\right)$ for $1 \mathrm{~h}$. Samples containing the cell suspension were washed twice in nanopure $\mathrm{H}_{2} \mathrm{O}$ (with a resistivity of $18.2 \mathrm{MW}$ This article is protected by copyright. All rights reserved. 
$\mathrm{cm}^{-1}$ ) for 20 min each. Samples were then dehydrated by passing them through a graded ethanol series $(20,40$, and $60 \%)(2 \mathrm{~mL})$ for $20 \mathrm{~min}$ on ice and then stained for $8 \mathrm{~h}$ with $2 \%$ uranyl acetate in $70 \%$ ethanol $(2 \mathrm{~mL})$. After staining, the cell blocks were further dehydrated by passing the samples through another graded ethanol series (80, 90 and $100 \%)$ for 15 min each $(2 \mathrm{~mL})$ on ice.

The embedding medium was prepared using London Resin Gold (ProSciTech). To embed the samples, each agar sample containing the cell suspension was incubated in $2 \mathrm{~mL}$ of $100 \%$ ethanol and LR gold monomer (1:1 ratio) for $8 \mathrm{~h}$ on ice, followed by a transfer to $100 \%$ ethanol and LR gold monomer (1:3 ratio) for $8 \mathrm{~h}$, then finally a transfer into the pure LR gold monomer for $8 \mathrm{~h}$. Each sample was then transferred into a gelatin capsule containing fresh LR gold monomer mixed with $1 \%$ dry benzoyl peroxide, which was then polymerized for $24 \mathrm{~h}$ at $4^{\circ} \mathrm{C}$. The final blocks were trimmed, then cut into ultrathin sections ( $50 \mathrm{~nm}$ thickness) using a Leica EM UC7 Ultramicrotome (Leica Microsystems, Wetzlar, Germany) with a diamond knife (Diatome, Pennsylvania, USA). Sections were placed onto 300 mesh copper grids and examined using a JEM 1010 instrument (JEOL). Approximately 40 TEM images were taken at $\times 10000$ and $\times 20000$ magnifications for each sample analysed.

\section{1 \\ Supporting Information}

Supporting Information is available from the Wiley Online Library or from the author.

\section{Acknowledgements}

X.L.G. would like to thank Cancéropôle Lyon Auvergne Rhône-Alpes (CLARA), Plan Cancer (C18038CS), and ARC (R17157CC) for their financial support. Funding from the Australian Research Council (ARC) Industrial Transformation Research Hubs Scheme (Project Number IH130100017) and

This article is protected by copyright. All rights reserved. 
ARC Industrial Transformation Training Centre (ITTC) scheme (Project number IC180100005) are gratefully acknowledged. D.P.L would like to acknowledge the Australian Institute of Nuclear Science and Engineering (AINSE) for travel support. J.-B F acknowledges funding from the SFB1027 (DFG).
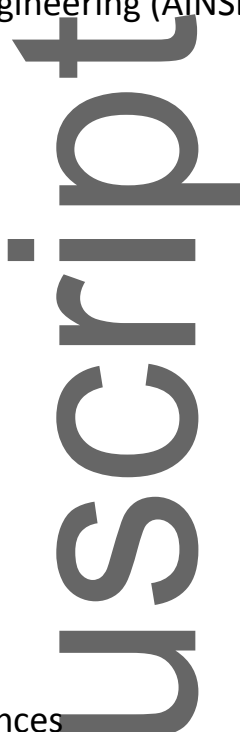

References

Received: ((will be filled in by the editorial staff))

Revised: ((will be filled in by the editorial staff))

Published online: ((will be filled in by the editorial staff))

[1] P. Nisar, N. Ali, L. Rahman, M. Ali, Z. K. Shinwari, JBIC Journal of Biological Inorganic Chemistry, 2019, 24, 929-941.

[2] Y. N. Slavin, J. Asnis, U. O. Häfeli, H. Bach, Journal of Nanobiotechnology, 2017, 15.

[3] D. Guarnieri, S. Sabella, O. Muscetti, V. Belli, M. A. Malvindi, S. Fusco, E. De Luca, P. P. Pompa, P. A. Netti, Nanoscale, 2014, 6, 10264.

[4] M. Werner, T. Auth, P. A. Beales, J. B. Fleury, F. Höök, H. Kress, R. C. Van Lehn, M. Müller, E. P. Petrov, L. Sarkisov, J.-U. Sommer, V. A. Baulin, Biointerphases, 2018, 13, 028501.

[5] S. Pogodin, M. Werner, J.-U. Sommer, V. A. Baulin, ACS Nano, 2012, 6, 10555-10561.

[6] J. Lin, L. Milao, G. Zhong, C.-H. Lin, R. Dargazangy, A. Alexander-Katz, Communications Biology, 2020, 3.

This article is protected by copyright. All rights reserved. 
[7] S. Burgess, Z. Wang, A. Vishnyakov, A. V. Neimark, Journal of Colloid and Interface Science, 2020, 561, 58-70.

[8] I. L. Bergin, F. A. Witzmann, International Journal of Biomedical Nanoscience and Nanotechnology, 2013, 3, 163

N

[9] A. Sukhanova, S. Bozrova, P. Sokolov, M. Berestovoy, A. Karaulov, I. Nabiev, Nanoscale Research Letters, 2018, 13.

[10] E. A. Ortiz-Benítez, N. Velázquez-Guadarrama, N. V. Durán Figueroa, H. Quezada, J. d. J. Olivares-Trejo, Metallomics, 2019, 11, 1265-1276.

[11] K. Zheng, M. I. Setyawati, D. T. Leong, J. Xie, ACS Nano, 2017, 11, 6904-6910.

[12] X. Xing, W.Ma, X. Zhao, J. Wang, L. Yao, X. Jiang, Z. Wu, Langmuir, 2018, 34, 1258312589.

[13] Y. Zhou, Y. Kong, S. Kundu, J. D. Cirillo, H. Liang, Journal of Nanobiotechnology, 2012, 10, 19.

[14] D. MubarakAli, N. Thajuddin, K. Jeganathan, M. Gunasekaran, Colloids and Surfaces B: Biointerfaces, 2011, 85, 360-365.

[15] V. D. Badwaik, L. M. Vangala, D. S. Pender, C. B. Willis, Z. P. Aguilar, M. S. Gonzalez, R. Paripelly, R. Dakshinamurthy, Nanoscale Research Letters, 2012, 7, 623.

[16] C. Bankien, R. K. Matharu, Y. K. Cheong, G. G. Ren, E. Cloutman-Green, L. Ciric, Scientific Reports, 2019, 9.

This article is protected by copyright. All rights reserved. 
[17] S. Shaikh, N. Nazam, S. M. D. Rizvi, K. Ahmad, M. H. Baig, E. J. Lee, I. Choi, International Journal of Molecular Sciences, 2019, 20, 2468.

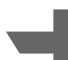

[18] Y. Zhang, T. P. Shareena Dasari, H. Deng, H. Yu, Journal of Environmental Science and Health, Part C, 2015, 33, 286-327.

.

[19] E. P. Ivanova, J. Hasan, H. K. Webb, G. Gervinskas, S. Juodkazis, V. K. Truong, A. H. Wu, R. N. Lamb, V. A. Baulin, G. S. Watson, Nat. Commun., 2013, 4, 2838.

[20] D. P. Linklater, M. De Volder, V. A. Baulin, M. Werner, S. Jessl, M. Golozar, L. Maggini, S. Rubanov, E. Hanssen, S. Juodkazis, E. P. Ivanova, ACS Nano, 2018, 12, 6657-6667.

[21] E. P. Ivanova, J. Hasan, H. K. Webb, V. K. Truong, G. S. Watson, J. A. Watson, V. A. Baulin, S. Pogodin, J. Y. Wang, M. J. Tobin, C. Löbbe, R. J. Crawford, Small, 2012, 8, 2489-2494.

[22] Y. J.Hu, B.J. Cowling, K. Fukuda, The Lancet Infectious Diseases, 2018, 18, 597-598.

[23] Y. Pan, J.Zeng, L. Li, J. Yang, Z. Tang, W. Xiong, Y. Li, S. Chen, Z. Zeng, mSystems, 2020, 5.

[24] S. Pogodin, J. Hasan, Vladimir A. Baulin, Hayden K. Webb, Vi K. Truong, The H.

Phong Nguyen, V. Boshkovikj, Christopher J. Fluke, Gregory S. Watson, Jolanta A. Watson, Russell J. Crawford, Elena P. Ivanova, Biophysical Journal, 2013, 104, 835-840.

[25] D. E. Mainwaring, S. H. Nguyen, H. Webb, T. Jakubov, M. Tobin, R. N. Lamb, A. H. F. Wu, R. Marchant, R. J. Crawford, E. P. Ivanova, Nanoscale, 2016, 8, 6527-6534.

This article is protected by copyright. All rights reserved. 
[26] E. P. Ivanova, J. Hasan, H. K. Webb, G. Gervinskas, S. Juodkazis, V. K. Truong, A. H. F. Wu, R. N. Lamb, V. A. Baulin, G. S. Watson, J. A. Watson, D. E. Mainwaring, R. J. Crawford, Nat. Commun., 2013, 4.

[27] C. M. Bhadra, M. Werner, V. A. Baulin, V. K. Truong, M. A. Kobaisi, S. H. Nguyen, A. Balcytis, S. Juodkazis, J. Y. Wang, D. E. Mainwaring, R. J. Crawford, E. P. Ivanova, NanoMicro Letters, 2018, 10.

[28] J. V.Wandiyanto, S. Cheeseman, V. K. Truong, M. A. Kobaisi, C. Bizet, S. Juodkazis, H. Thissen, R. J. Crawford, E. P. Ivanova, Journal of Materials Chemistry B, 2019, 7, 44244431

[29] B. Y.Moghadam, W.-C. Hou, C. Corredor, P. Westerhoff, J. D. Posner, Langmuir, 2012, 28, $16318-16326$.

[30] E. M. V. Hoek, G. K. Agarwal, Journal of Colloid and Interface Science, 2006, 298, 50-58.

[31] J.D. Olarte-Plata, G. Brekke-Svaland, F. Bresme, Nanoscale, 2020, 12, 11165-11173.

[32] T. Lunnoo, J. Assawakhajornsak, T. Puangmali, The Journal of Physical Chemistry C, 2019, $123,3801-3810$.

[33] E. Porret, L. Sancey, A. Martín-Serrano, M. I. Montañez, R. Seeman, A. Yahia-Ammar, H. Okuno, F. Gomez, A. Ariza, N. Hildebrandt, J.-B. Fleury, J.-L. Coll, X. Le Guével, Chemistry of Materials, 2017, 29, 7497-7506.

[34] Y. Guo, E. Terazzi, R. Seemann, J. B. Fleury, V. A. Baulin, Science Advances, 2016, 2, e1600261.

This article is protected by copyright. All rights reserved. 
[35] K. L. Chen, G. D. Bothun, Environmental Science \& Technology, 2013, 48, 873-880.

[36] E. Giovanetli, E. Muro, G. Sitbon, M. Hanafi, T. Pons, B. Dubertret, N. Lequeux, Langmuir, 2012, 28, 15177-15184.

[37] Y. Li, Y. Xu, C. C. Fleischer, J. Huang, R. Lin, L. Yang, H. Mao, Journal of Materials

Chemistry B, 2018, 6, 9-24.

[38] W. Pajerski, D. Ochonska, M. Brzychczy-Wloch, P. Indyka, M. Jarosz, M. Golda-Cepa, Z. Sojka, A. Kotarba, Journal of Nanoparticle Research, 2019, 21.

[39] J. Bresee, C. M. Bond, R. J. Worthington, C. A. Smith, J. C. Gifford, C. A. Simpson, C. J. Carter, G. Wang, J. Hartman, N. A. Osbaugh, R. K. Shoemaker, C. Melander, D. L. Feldheim, Journal of the American Chemical Society, 2014, 136, 5295-5300.

[40] Y. Zhao, X. Jiang, Nanoscale, 2013, 5, 8340.

[41] Z. V. Feng, I. L. Gunsolus, T. A. Qiu, K. R. Hurley, L. H. Nyberg, H. Frew, K. P. Johnson, A. M. Vartanian, L. M. Jacob, S. E. Lohse, M. D. Torelli, R. J. Hamers, C. J. Murphy, C. L. Haynes, Chemical Science, 2015, 6, 5186-5196.

[42] J. T. Buchman, A. Rahnamoun, K. M. Landy, X. Zhang, A. M. Vartanian, L. M. Jacob, C. J. Murphy, R. Hernandez, C. L. Haynes, Environmental Science: Nano, 2018, 5, 279-288.

[43] A. E. Nel, L. Mädler, D. Velegol, T. Xia, E. M. V. Hoek, P. Somasundaran, F. Klaessig, V.

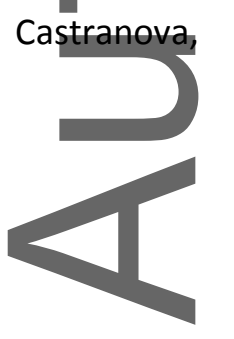
M. Thompson, Nature Materials, 2009, 8, 543-557.

This article is protected by copyright. All rights reserved. 
[44] A. H. Bahrami, M. Raatz, J. Agudo-Canalejo, R. Michel, E. M. Curtis, C. K. Hall, M.

Gradzielski, R. Lipowsky, T. R. Weikl, Advances in Colloid and Interface Science, 2014, 208, 214-224.

[45] M.Deserno, T. Bickel, Europhysics Letters (EPL), 2003, 62, 767-774.

[46] K. Xiong, J.Zhao, D. Yang, Q. Cheng, J. Wang, H. Ji, Soft Matter, 2017, 13, 4644-4652.

[47] C. van derWel, A. Vahid, A. Šarić, T. Idema, D. Heinrich, D. J. Kraft, Scientific Reports, 2016,

[48] A. Vahid, A. Šarić, T. Idema, Soft Matter, 2017, 13, 4924-4930.

[49] B. Reynwar, G. Illya, V. A. Harmandaris, M. M. Müller, K. Kremer, M. Deserno, Nature, 2007, 447, 461-464.

[50] W.-C. Hou, B. Y. Moghadam, C. Corredor, P. Westerhoff, J. D. Posner, Environmental Science \& Technology, 2012, 46, 1869-1876.

[51] Y. Bunga, R. Kataky, Journal of Electroanalytical Chemistry, 2020, 872, 114302.

[52] H. Zhang, X. Wei, L. Liu, Q. Zhang, W. Jiang, Science of The Total Environment, 2019, 673, 414-423.

[53] J. K. Sheavly, J. A. Pedersen, R. C. Van Lehn, Nanoscale, 2019, 11, 2767-2778.

[54] S. Zhang, A. Nelson, P. A. Beales, Langmuir, 2012, 28, 12831-12837.

[55] M.Deserno, Physical Review E, 2004, 69.

This article is protected by copyright. All rights reserved. 
[56] M. Stefanic, K. Ward, H. Tawfik, R. Seemann, V. Baulin, Y. Guo, J.-B. Fleury, C. Drouet, Biomaterials, 2017, 140, 138-149.

[57] O. Le Bihan, P. Bonnafous, L. Marak, T. Bickel, S. Trépout, S. Mornet, F. De Haas, H. Talbot, J.-C. Taveau, O. Lambert, Journal of Structural Biology, 2009, 168, 419-425.

[58] A. Dias, M.Werner, K. R. Ward, J.-B. Fleury, V. A. Baulin, Nanoscale, 2019, 11, 2282-2288.

[59] Y. Zhao, X. Sun, G. Zhang, B. G. Trewyn, I. I. Slowing, V. S. Y. Lin, ACS Nano, 2011, 5, 13661375.

[60] L. C. J. Thomassen, V. Rabolli, K. Masschaele, G. Alberto, M. Tomatis, M. Ghiazza, F. Turci, E. Breynaert, G. Martra, C. E. A. Kirschhock, J. A. Martens, D. Lison, B. Fubini, Chemical Research in Toxicology, 2011, 24, 1869-1875.

[61] Y. Liu, R. Mark Worden, Biochimica et Biophysica Acta (BBA) - Biomembranes, 2015, 1848, $67-75$.

[62] Y. Roiter, M. Ornatska, A. R. Rammohan, J. Balakrishnan, D. R. Heine, S. Minko, Nano Letters, 2008, 8, 941-944.

[63] J. Park, J. Nam, N. Won, H. Jin, S. Jung, S. Jung, S.-H. Cho, S. Kim, Advanced Functional Materials, 2011, 21, 1558-1566.

[64] R. J. Crawford, H. K. Webb, V. K. Truong, J. Hasan, E. P. Ivanova, Advances in Colloid and Interface Science, 2012, 179-182, 142-149.

[65] D. P. Linklater, V. A. Baulin, S. Juodkazis, R. J. Crawford, P. Stoodley, E. P. Ivanova, Nature Reviews Microbiology, 2020, 10.1038/s41579-020-0414-z.

This article is protected by copyright. All rights reserved. 
[66] F. Zou, H. Zhou, D. Y. Jeong, J. Kwon, S. U. Eom, T. J. Park, S. W. Hong, J. Lee, ACS Applied Materials \& Interfaces, 2017, 9, 1343-1351.

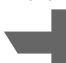

[67] L. SU, Y. Yu, Y. Zhao, F. Liang, X. Zhang, Scientific Reports, 2016, 6.

[68] P. A. Tran, N. O'Brien-Simpson, J. A. Palmer, N. Bock, E. C. Reynolds, T. J. Webster, A.

Deva, W.A. Morrison, A. J. O'Connor, International Journal of Nanomedicine, 2019,

Volume 14, 4613-4624.

[69] M. Deserno, W. M. Gelbart, The Journal of Physical Chemistry B, 2002, 106, 5543-5552.

[70] D. J. Lipomi, R. V. Martinez, L. Cademartiri, G. M. Whitesides in Polymer Science: A Comprehensive Reference 10.1016/b978-0-444-53349-4.00180-1 211-231 (Elsevier, 2012).

[71] H. Bayley, B. Cronin, A. Heron, M. A. Holden, W. L. Hwang, R. Syeda, J. Thompson, M. Wallace, Molecular BioSystems, 2008, 4, 1191.

[72] J. N. Vargas, R. Seemann, J.-B. Fleury, Soft Matter, 2014, 10, 9293-9299.

[73] D. Needham, K. Kinoshita, A. Utoft, Micromachines, 2019, 10, 105.

[74] H. C. Leggett, C. K. Cornwallis, S. A. West, PLoS Pathogens, 2012, 8, e1002512.

[75] T. Passon, The Synergist, 2007, 18, 35.

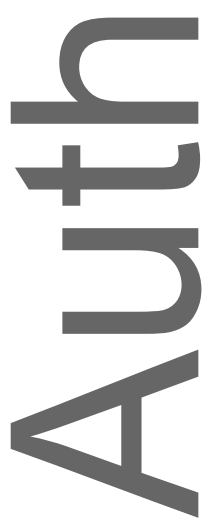

This article is protected by copyright. All rights reserved. 


\section{A Small NPs (<10 nm)}

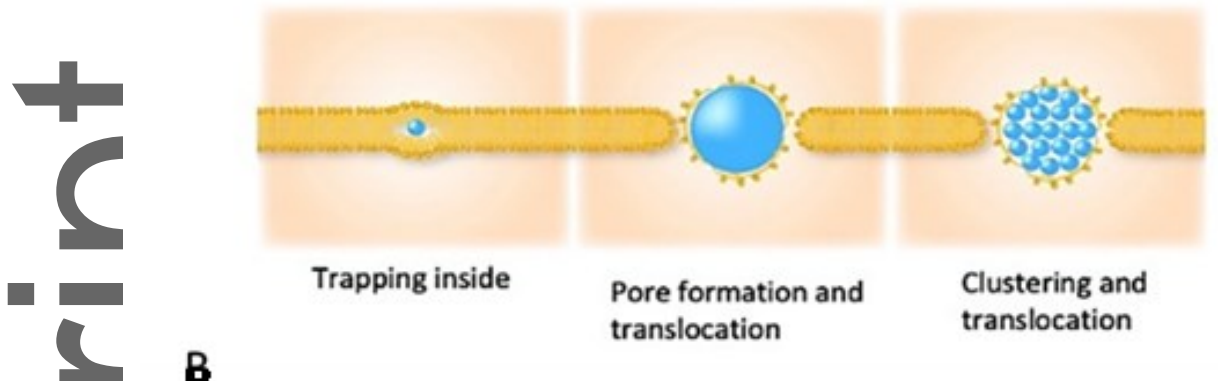

B

\section{Large NPs (>10 nm)}

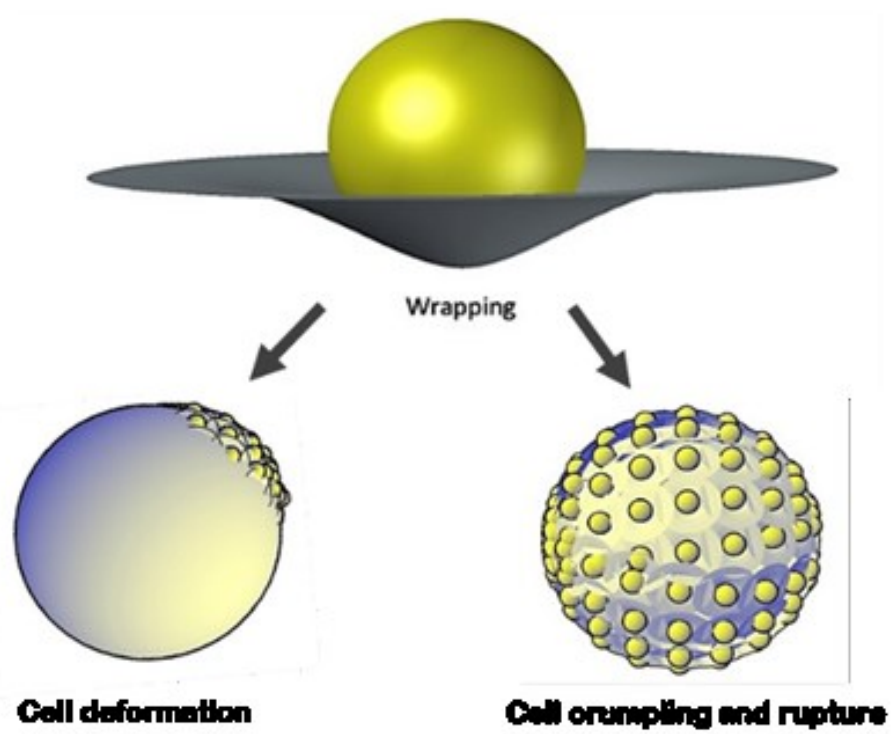

Figure 1. Two separate mechanisms of NP-membrane interactions. A) Small NPs or clusters of NPs, with overall diameter less than the thickness of the phospholipid bilayer $(<10 \mathrm{~nm})$, are either trapped inside the bilayer or form a pore, enabling translocation ${ }^{[34]}$. B) Large NPs, with diameter greater than the thickness of the cell membrane $(>10 \mathrm{~nm})$ are wrapped by the membrane, regardless of surface chemistry ${ }^{[6]}$. The adhesion of large NPs to the lipid membrane leads to cell deformation and/or crumpling as the elasticity of the membrane comes into play. The degree of membrane deformation depends on the balance between the energetic gain attributed to maximisation of the contact area between the lipid membrane and the NP and the free energy cost of the membrane deformation ${ }^{[76]}$.

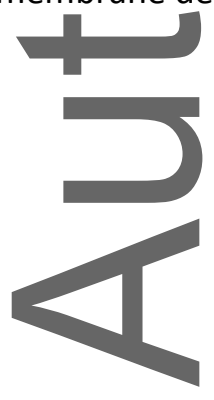

This article is protected by copyright. All rights reserved. 
A

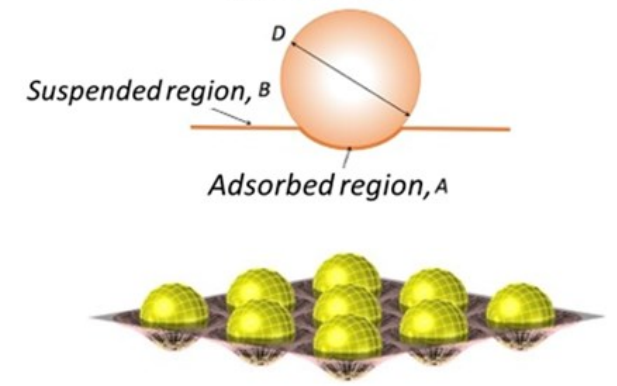

More tension

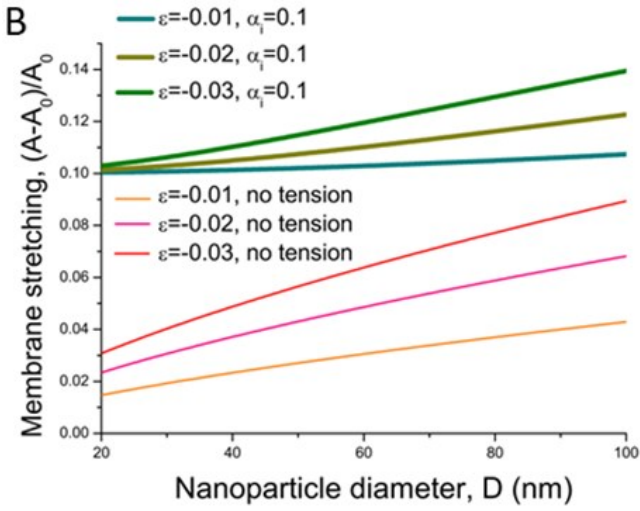

D

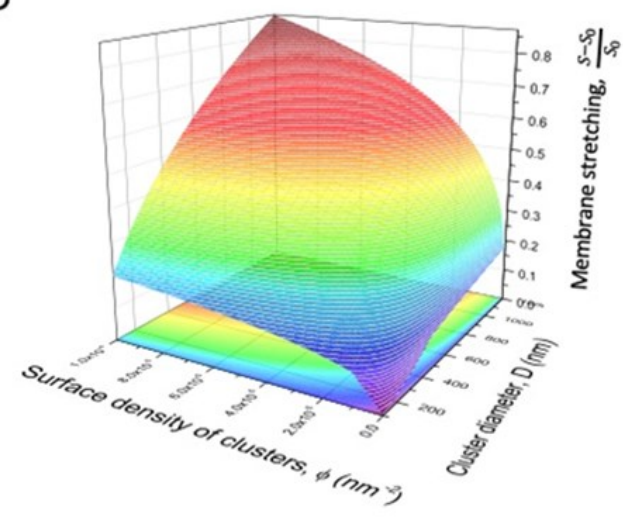

Cluster

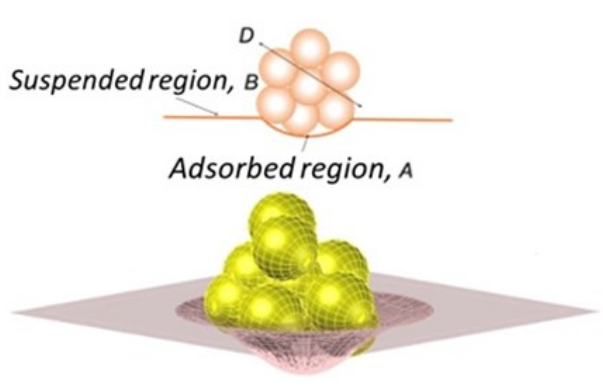

Less tension

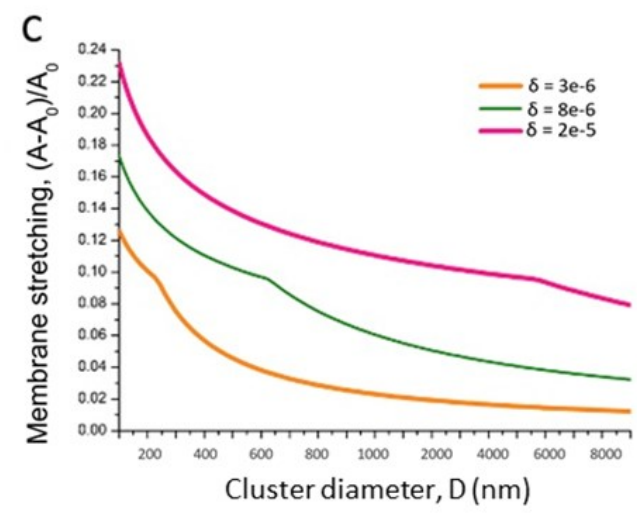

$E$

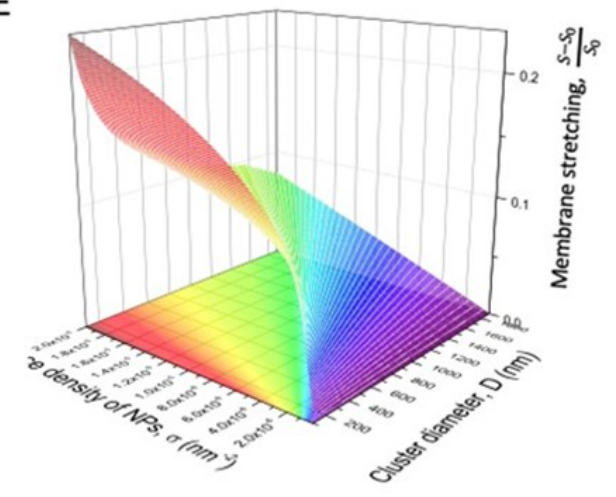

Figure 2. Global stretching of a lipid bilayer by individual and clustered NPs. A) Schematic representation of a layer adsorbed to NPs of diameter, D and two membrane regions: adsorbed, A and suspended, B. Individual NPs are arranged in repetitive cell units. The average surface density of adsorbed NPs corresponds to a distance between NPs, which determines the area of the layer per NP. The same number of NPs grouped in a cluster of 9 NPs for the same surface density of NPs, $\sigma$. NPs may group in clusters to reduce tension. B) Membrane stretching as a function of NPs diameters for a fixed surface density of NPs at the membrane, $\sigma=10^{-4} \mathrm{~nm}^{-2}$ (i.e. the distance between centers that corresponds to full packing for $100 \mathrm{~nm}$ NPs) for tensionless membrane and for a

This article is protected by copyright. All rights reserved. 
membrane under tension. C) Membrane stretching as a function of cluster diameter for fixed surface density of NPs. D) Cumulative membrane stretching $\alpha_{\mathrm{B}}$ as a function of the cluster diameter and surface density of clusters $\phi$. E) Cumulative membrane stretching as a function of the cluster diameter and surface density of NPs.

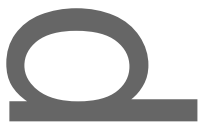

A

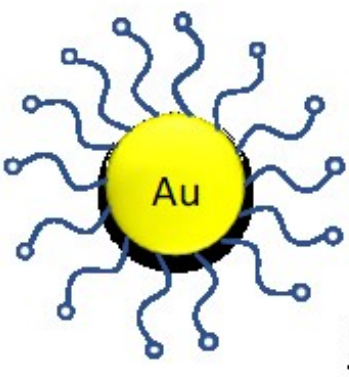

B

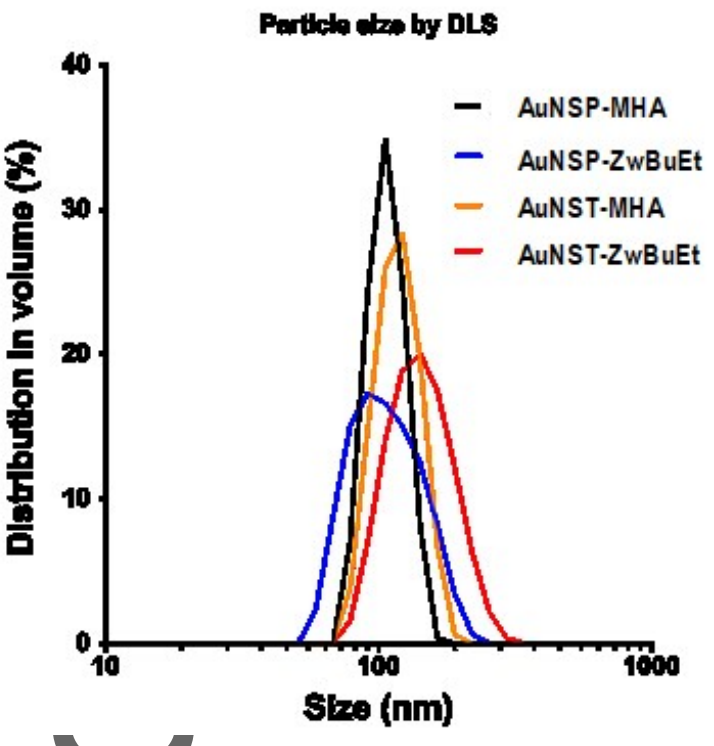

MHA<smiles>OC(O)CCCCCS</smiles>

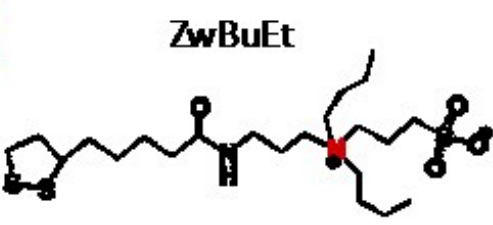
$\boldsymbol{d}$ $200 \mathrm{~nm}$

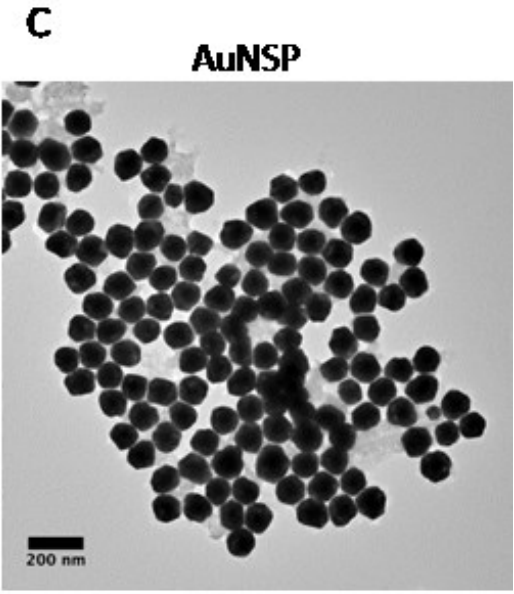

\section{AuNST}

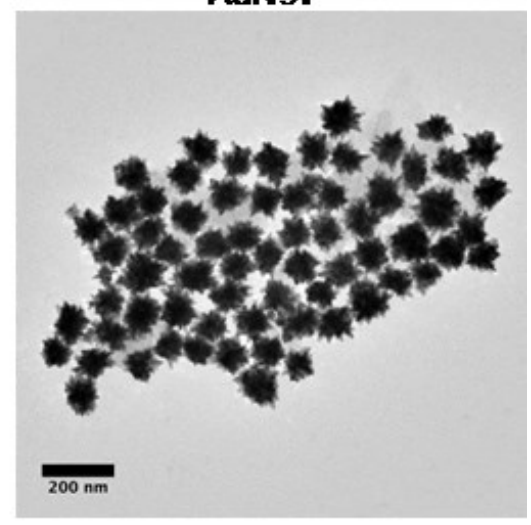

Figure 3. Characterisation of AuNSTs and AuNSPs. (A) Schematic depiction of gold surfaces coated with zwitterionic ligands MHA and ZwBuEt. (B) DLS measurements of the different AuNPs in water (pH 7). (C) TEM micrographs of AuNSPs and AuNSTs. AuNSTs show stars of uniform conformation with average diameter of $103.9 \pm 11.9 \mathrm{~nm}$, an average of $12 \pm 2 \mathrm{~nm}$ spikes and spike length of $18.2 \pm$ $3.7 \mathrm{~nm}$. AuNSPs are uniformly $100 \pm 20 \mathrm{~nm}$.

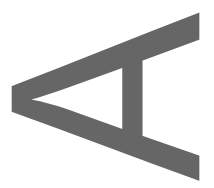

This article is protected by copyright. All rights reserved. 

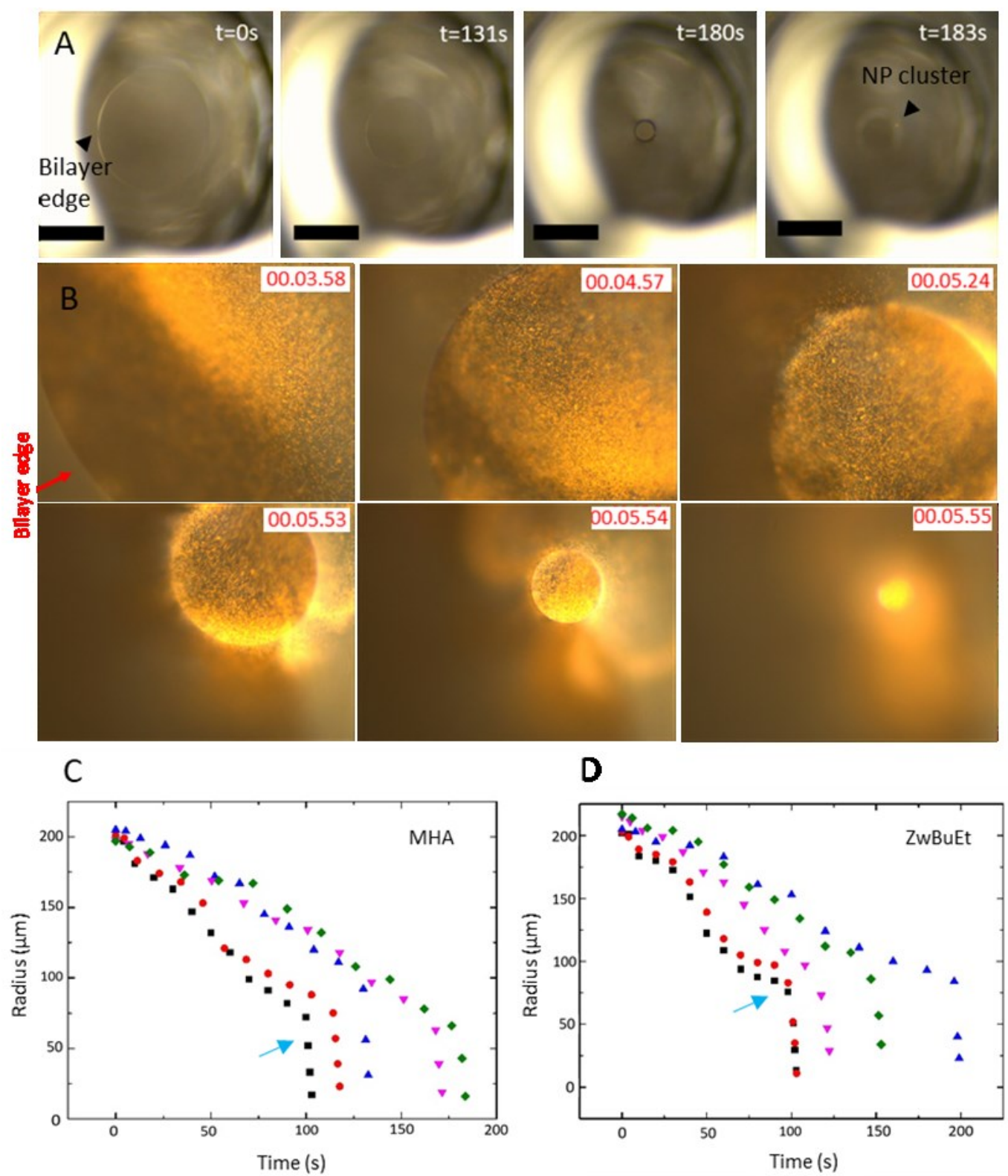

Figure 4. Optical microscopy visualization of the forces placed on the phospholipid membrane. (A) Time series of the bilayer contraction due to the presence of $100 \mu \mathrm{g} \mathrm{Au} \mathrm{mL}^{-1}$ of $100 \mathrm{~nm}$ AuNSP-MHA in contact with the bilayer (bilayer diameter is $\sim 1 \mathrm{~mm}$ ). An AuNSP agglomerate is visible in the last image $(t=183 \mathrm{~s})$, indicated by the black arrow. The scale bar is $500 \mu \mathrm{m}$ and the magnification is $\times 5$. At this magnification single NPs are not visible under dark field microscopy. (B)Time-lapse series of micrographs of the-lipid bilayer interacting with the AuNSPs over 6 min observed from top view with dark field microscopy, magnification $\times 50$ in the presence of $100 \mu \mathrm{g} \mathrm{Au} \mathrm{mL}{ }^{-1}$ of AuNSP-MHA. At this high concentration, the bilayer bursts due to interaction with the AuNPs when the radius of the

This article is protected by copyright. All rights reserved. 
bilayer has been reduced to approximately $75 \mu \mathrm{m}$ (sharp drop of bilayer radii to 0 correlated to bursting, indicated by cyan arrow). (C) The measured radius as function of time for 5 separate lipid bilayers in contact with $100 \mu \mathrm{g} \mathrm{Au} \mathrm{mL} \mathrm{L}^{-1}$ AuNSP-MHA and (D) the measured radius as function of time

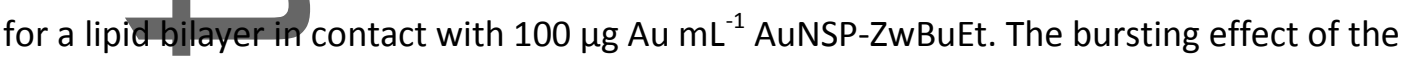
phospholipid membrane is consistently observed between 100 and 200 seconds as confirmed using the two different types of the NPs. The movie showing the squeezing and bursting of the lipid bilayer can be found at Supplementary Movie File 2.

-

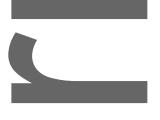

A
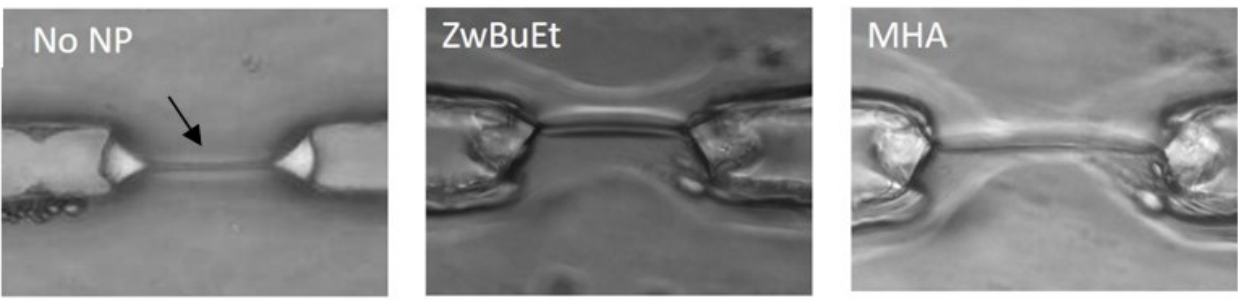

B
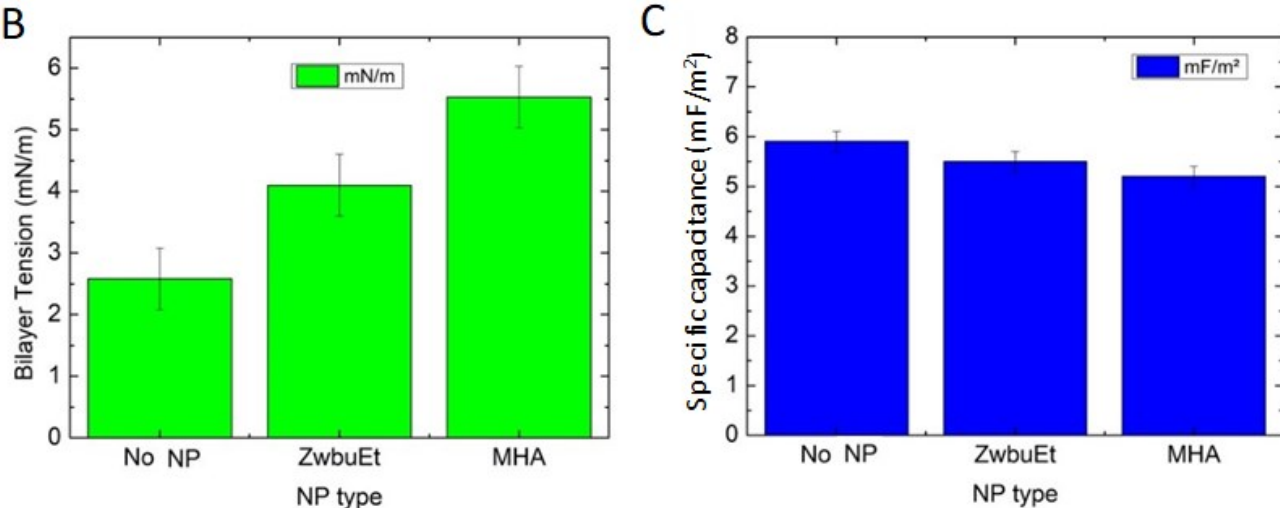

Figure 5. (A) The lipid membrane in a microfluidic device observed by optical microscopy, indicated by the black arrow and the lipid bilayer in contact with AuNSP-ZwBuEt and AuNSP-MHA. A distinct difference in the contact angle is visible in the presence of the two AuNP. (B) Membrane tension as function of the two types of quasi-spherical AuNSP adsorption on the lipid membrane. (C) The measured specifie capacitance of the bilayer in contact with AuNSP-MHA and AuNSP-ZwBuEt. Capacitance measurements, $\mathrm{Cs}=\mathrm{C} / \mathrm{A}$. A concentration of $100 \mu \mathrm{g} \mathrm{Au} \mathrm{mL} \mathrm{L}^{-1}$ of AuNSP-MHA and ZwBuEt was used to measure the changes in membrane tension of the model membrane. From the electrostatic point of view, this is equivalent to a plane dielectric (i.e., the bilayer) in series with a spherical dielectric (AuNP), which is leading to a decrease in the overall capacitance.

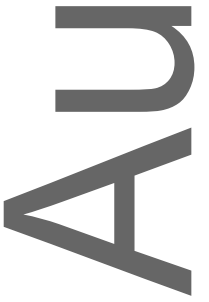

This article is protected by copyright. All rights reserved. 

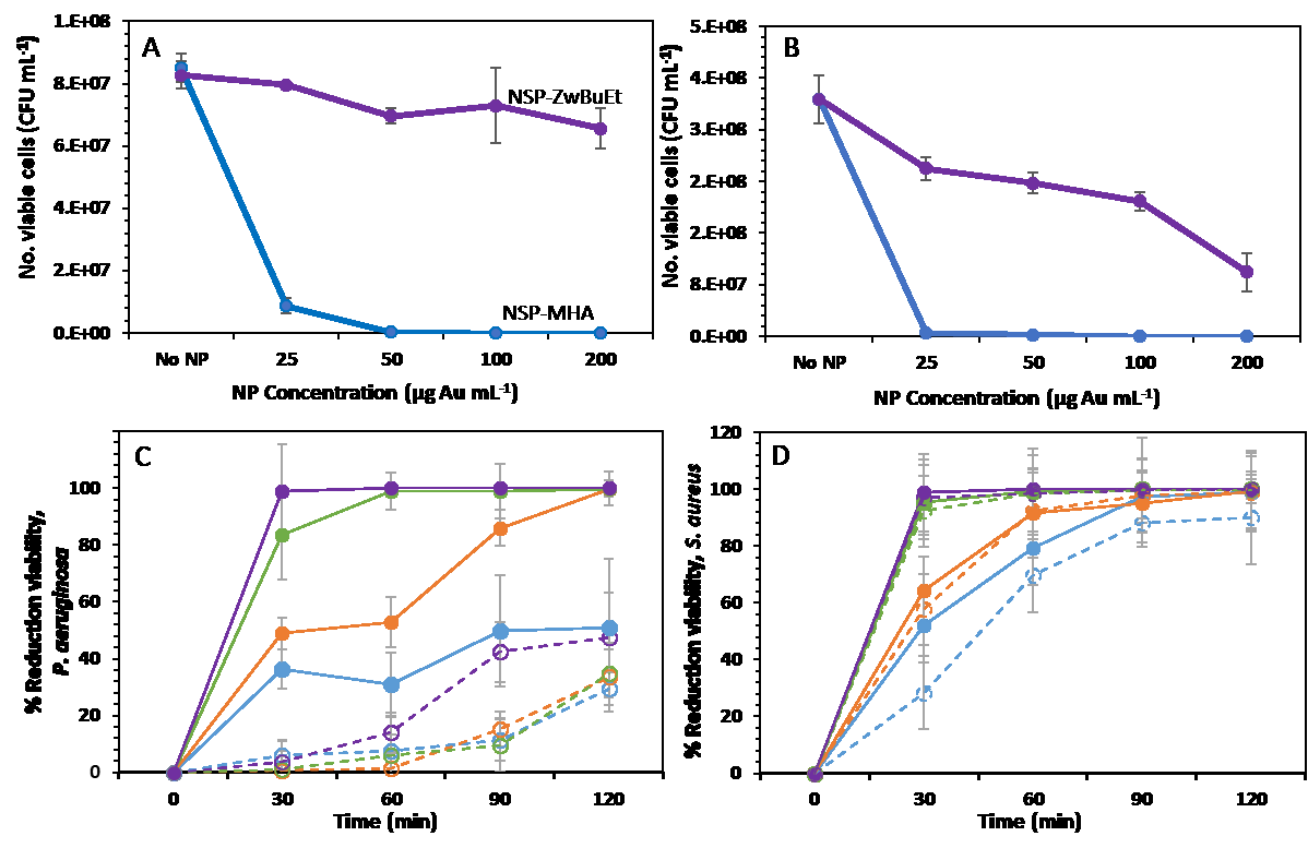

MHA $\longrightarrow 25 \longrightarrow 50 \longrightarrow 100 \longrightarrow 200$ Au $\mathrm{gg} \mathrm{mL}^{-1}$

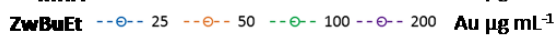

E

P. aeruginosa

S. aureus

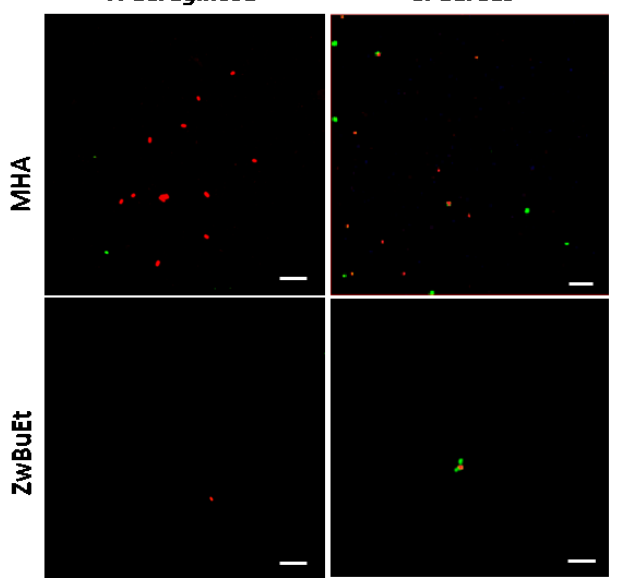

Figure 6. Concentration-dependent antibacterial activity of AuNSP towards $(A) P$. aeruginosa and (B) $S$. aureus expressed as the number of colony-forming units per $\mathrm{mL}\left(\mathrm{CFU} \mathrm{mL} \mathrm{m}^{-1}\right.$ ). NPs were incubated with bacteria at concentrations of 25, 50, 100 and $200 \mu \mathrm{g} \mathrm{Au} \mathrm{mL} \mathrm{m}^{-1}$ for $2 \mathrm{~h}$. AuNSP showed strong concentration-dependent antimicrobial activity against both bacterial strains ${ }^{[77]}$. (C-D) The kinetics of bactericidalefficiency of the AuNPs over time investigated at specific time points of 0.5, 1, 1.5 and 2 h. AuNSPs showed a steady increase in their antibacterial efficiency over the course of $2 \mathrm{~h}$. AuNSP at

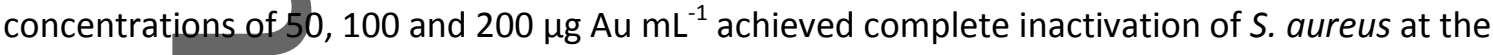
maximum incubation time. AuNSP-MHA achieved $100 \%$ inactivation of $P$. aeruginosa cells at

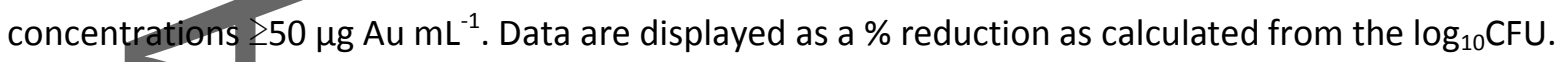

(E) Representative confocal laser scanning micrographs (CLSM) of $P$. aeruginosa and $S$. aureus

This article is protected by copyright. All rights reserved. 
incubated with AuNSP-MHA and AuNSP-ZwBuEt. CLSM scale bar is $5 \mu \mathrm{m}$. Bacterial suspensions were incubated for $2 \mathrm{~h}$ with $100 \mu \mathrm{g} \mathrm{Au} \mathrm{mL}{ }^{-1}$ AuNPs and subsequently stained with propidium iodide (PI) and Syto $9^{\circ}$. PI (red) indicates non-viable bacterial cells caused by membrane disruption and Syto $9^{\circ}$ (green) indicates viable bacteria.
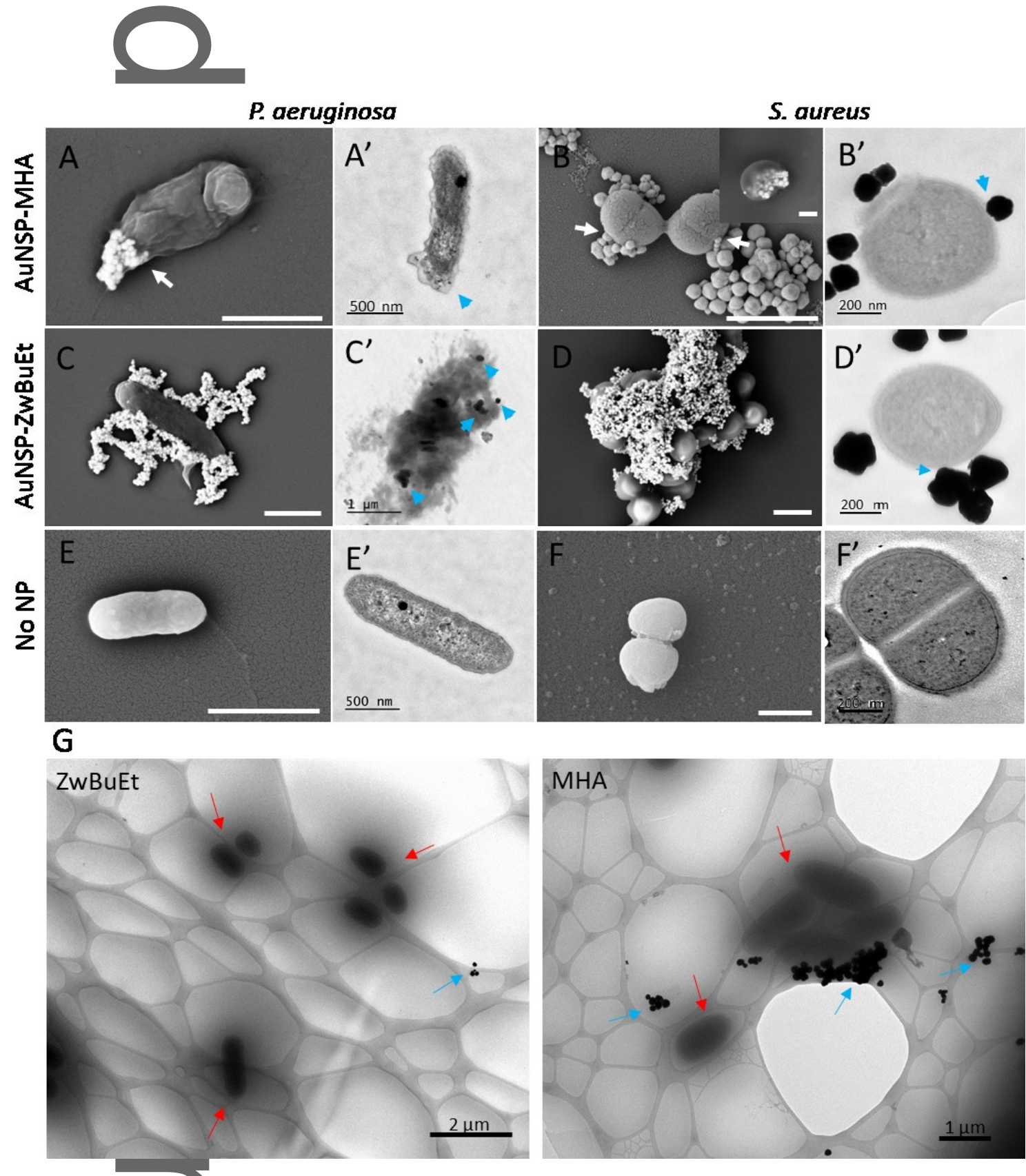

Figure 7. Morphology of bacterial cells post-incubation with AuNPs. (A-F) SEM and TEM micrographs of the changes in cell morphology of $P$. aeruginosa and $S$. aureus bacteria incubated with $200 \mu \mathrm{g} / \mathrm{mL}$ AuNSPs for a period of $2 \mathrm{~h}$ in comparison to healthy cell morphology. The white arrows (SEM images) and blue arrows (TEM images) indicate areas of membrane deformation due to AuNP

This article is protected by copyright. All rights reserved. 
adsorption. Interaction between $P$. aeruginosa and AuNSPs lead to the formation of membrane blebbing (indicated by blue arrow, $A^{\prime}$ ) and the complete rupture of the bacterial cell $\left(C^{\prime}\right)$. AuNSPs were observed to adsorb onto the $S$. aureus cell membrane ( $\left.D, D^{\prime}\right)$ and cause membrane deformation ( $B$ ) and eventual loss of cellular integrity ( $B$, inset). (E) Cryo-TEM analysis of the AuNP affinity for and attachment to bacterial membranes. $P$. aeruginosa was incubated with each NP AuNSP-ZwBuEt and AuNSP-MHA in PBS buffer for a brief period (15 min) and then $10 \mu \mathrm{L}$ aliquots were vitrified and (G) visualised using Cryo-TEM at an accelerating voltage of $200 \mathrm{kV}$. Red arrows indicate bacterial cells and blue arrows point out single or clustered NPs. The bacteria/NP suspensions are vitrified on a lacy carbon grid, which provides the lattice structure in the background. SEM Scale bars are $1 \mu \mathrm{m}$.

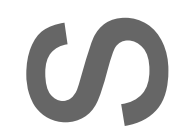

The mechanism of antimicrobial action for nanoparticles that are unable to be translocated across the bacterial cell membrane by the passive or active processes that exist for mammalian cells remains obscure. We demonstrate that the increase of membrane tension provoked by the adsorption of nanoparticles is responsible for mechanical deformation of the membrane that leads to bactericalcell rupture and death.

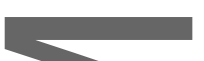

D. P. Linklater ${ }^{1,2}$, V.A. Baulin ${ }^{3}$, X. Le Guével ${ }^{4}$, J.B. Fleury ${ }^{5}$, E. Hanssen ${ }^{6}$, T.H.P. Nguyen ${ }^{7}$, S. Juodkazis ${ }^{2}$, G. Bryant $^{1}$, R.J. Grawford ${ }^{1}$, P. Stoodley ${ }^{8}$, E. P. Ivanova ${ }^{1 *}$

\section{Antibacterial action of nanoparticles by lethal stretching of bacterial cell membranes}
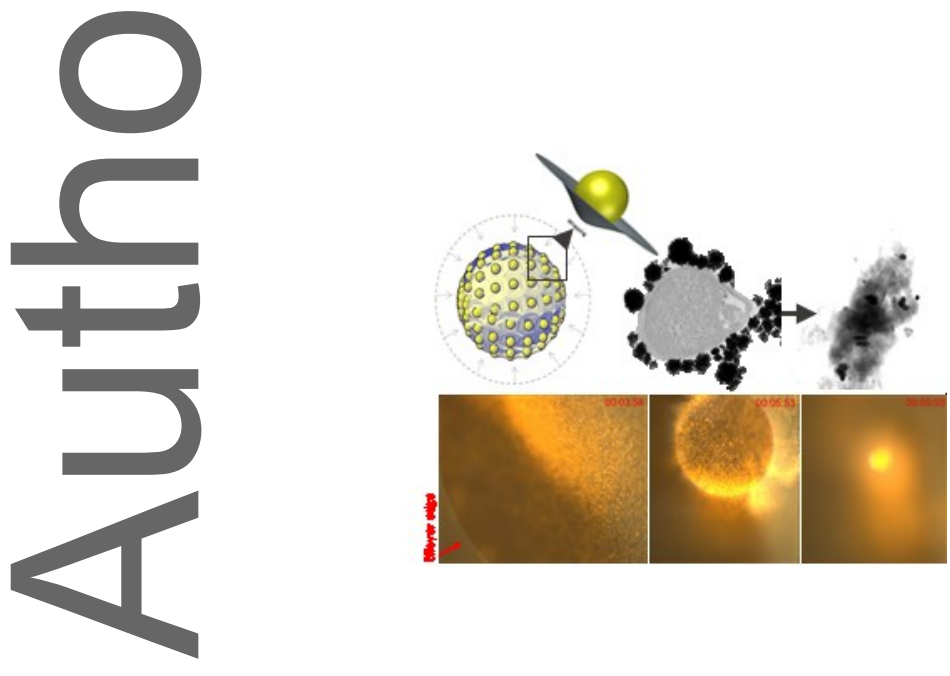

This article is protected by copyright. All rights reserved. 


\section{University Library}

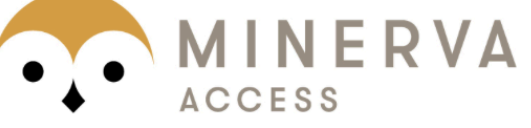

A gateway to Melbourne's research publications

Minerva Access is the Institutional Repository of The University of Melbourne

Author/s:

Linklater, DP;Baulin, VA;Le Guevel, X;Fleury, J-B;Hanssen, E;Nguyen, THP;Juodkazis,

S;Bryant, G;Crawford, RJ;Stoodley, P;Ivanova, EP

Title:

Antibacterial Action of Nanoparticles by Lethal Stretching of Bacterial Cell Membranes

Date:

2020-12-28

\section{Citation:}

Linklater, D. P., Baulin, V. A., Le Guevel, X., Fleury, J. -B., Hanssen, E., Nguyen, T. H. P., Juodkazis, S., Bryant, G., Crawford, R. J., Stoodley, P. \& Ivanova, E. P. (2020). Antibacterial Action of Nanoparticles by Lethal Stretching of Bacterial Cell Membranes. ADVANCED MATERIALS, 32 (52), https://doi.org/10.1002/adma.202005679.

Persistent Link:

http://hdl.handle.net/11343/276603 